\title{
Inflation Dynamics: Expectations, Structural Breaks and Global Factors
}

PIERRE L. SIKLOS

Wilfrid Laurier University and Balsillie School of International Affairs *

\begin{abstract}
There is no consensus over the importance of "global forces" on inflation. This study explores the role of structural breaks in the inflation process, and their timing, whether it is common across countries, and the extent to which 'global forces' are relevant. Three conclusions stand out. Global inflation impacts inflation in both AE and EME, but the impact is more heterogeneous than existing narratives have argued. One's interpretation of global influences on domestic inflation differs, according to whether poorly performing economies in inflation terms are considered as opposed to the standard practice of examining mean inflation performance. A focus on observed inflation alone ignores that inflation expectations, including a global version of this variable, also plays a critical in inflation dynamics. Finally, there are significant spillovers in inflation between AE and EME, but these too are sensitive according to relative inflation performance. Some policy implications are also drawn.
\end{abstract}

Keywords: Inflation, Globalization, monetary policy, Vector autoregressions, local projections, quantile regressions

JEL Classifications: E31, E52, E58, C31, C32

"Inflation has risen sharply this year, from 2.1\% in December [2007] to 3.3\% in May [2008]. ...Those sharp changes reflect development in the global balance of demand and supply for food and energy..." (King 2008)

"Inflation has remained high, largely reflecting sharp increases in the prices of globally traded commodities." (Bernanke 2008)

“The world as a whole cannot import inflation..." (Wolf 2008)

\footnotetext{
* Department of Economics, Wilfrid Laurier University and Balsillie School of International Affairs, psiklos@wlu.ca, pierrelsiklos.com. A previous version of the paper was presented at Mardi Dungey Memorial Research Conference at George Washington University, February 21, 2020. I am grateful for the comments received from Conference participants.

(C) 2020 Pierre L. Siklos. Licensed under the Creative Commons Attribution - Noncommercial 3.0 Licence (http://creativecommons.org/licenses/by-nc/3.0/. Available at http: //rofea.org.
} 


\section{Introduction}

Central bankers are fond of regularly telling audiences that our understanding of the dynamics of inflation, not to mention inflation expectations, remains incomplete. For example, even before the financial crisis (GFC) ${ }^{1}$, Bernanke (2007) reminded his audience that "...we must understand better the historical variation in inflation expectations, the effect of this variation on actual inflation...". Yellen (2017), well after the worst of the GFC had passed, pointed out to a different audience that “...economists' understanding of exactly how and why inflation expectations change over time is limited."

Contributing perhaps to the confusion over what drives inflation dynamics is central bank communication of the kind in the opening remarks by King and Bernanke. As Wolf (2008) points out, the world cannot import inflation unless there exists "interplanetary trade" (Buiter 2008 , p. 87). A more sympathetic interpretation is that exchange rates, the quality of a nation's monetary policy strategy, external shocks considered 'global' in nature, to mention three factors that contain 'global' elements, contribute to creating confusion between relative and absolute price changes. ${ }^{2}$ The former is not inflation in the usual sense of the word; control of the latter is the primary concern of the monetary authorities.

One of the preoccupations of central bankers has been the role played by the forces of globalization and the challenges this poses for the ability of monetary policy to be responsive primarily to domestic economic conditions. The role of globalization is a line of enquiry prompted in part by the emergence of a global factor in inflation (e.g., Ciccarelli and Mojon 2010, Forbes 2019). Carney (2017), Governor of the Bank of England at the time, put it in the following terms: "...globalisation has been accompanied by a weakening of the relationship between domestic slack and inflation, and by a corresponding strengthening in the relationship between global forces and domestic prices." It is easy to see the origin of this concern over the role played by globalization in influencing inflation outcomes. Figure 1 shows mean annual average CPI inflation in a selection of advanced (AE) and emerging market economies (EME) since 1980 against an indicator of financial and trade globalization from the KOF Institute. Globalization in both trade and finance show steady rises, interrupted only by the GFC, and both indicators appear to stabilize thereafter while inflation in both AE and EME reveal a steady

\footnotetext{
1 The 2008-9 financial crisis is either referred to as the Global or Great Financial Crisis. In both cases, the acronym GFC applies and is referred to hereafter as such.

2 Ball and Mankiw (1995) argue that large relative price changes can have inflationary consequences (e.g., oil price shocks of the 1970s) although this appears to have been contradicted by similarly large oil price changes in 2011. More generally, there is no reason for relative price changes (e.g. due to globalization) to impact inflation (Rogoff 2006). Also unstated in the quotes at the beginning of the paper is that, for example, commodity prices are set in USD in international markets while inflation is evaluated in domestic currency terms.
} 


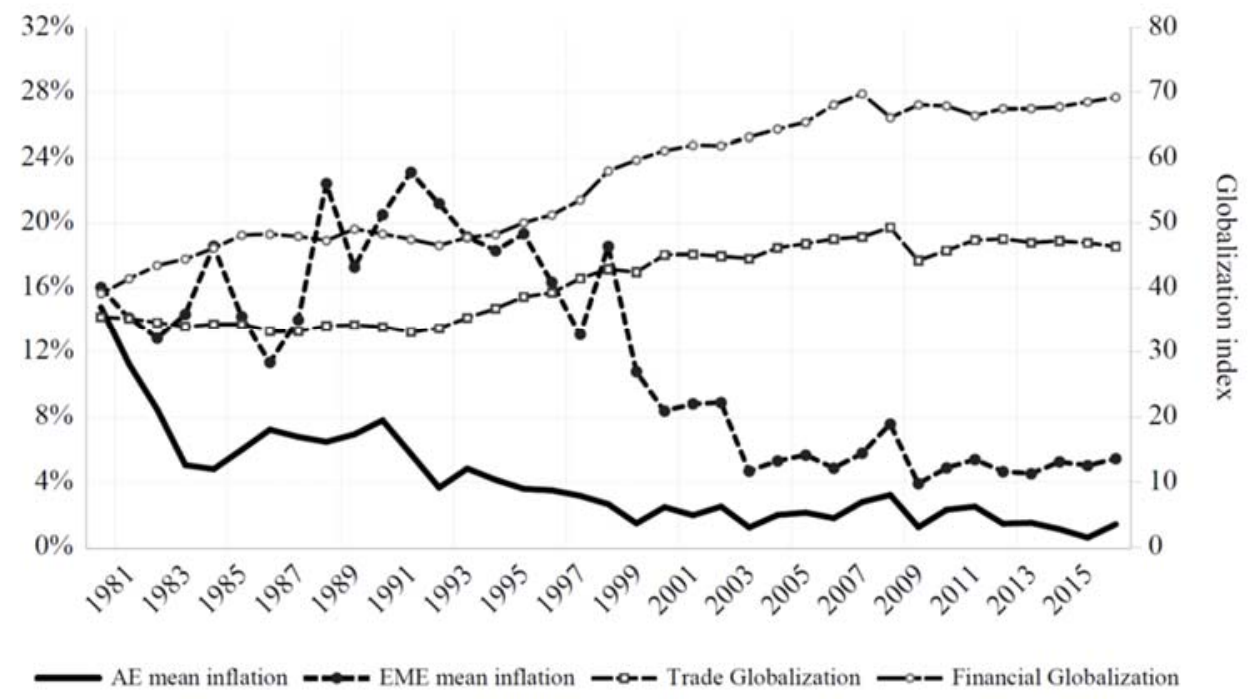

Note: Based on latest available data (2016) at the time of writing (September 2019) from the KOF (Swiss Institute) Globalization Index, available from https://kof.ethz.ch/en/forecasts-and-indicators/indicators/kof-globalisation-index.html. Inflation, measured on the left-hand scale, is annual rate of change in the CPI. See section 3 for data sources and coverage.

decline interrupted only by a bulge in inflation in the late 1980s. Of course, patterns such as these do not establish causation but provide a potential justification of the remark made by Governor Carney. As we shall see, however, there is no consensus over the importance of "global forces" on inflation, the focus of this study.

By the end of the 1980s academics and policy makers became convinced that central bank autonomy and, later, central bank transparency, together with a clear mandate for the central bank, would, combined with a floating exchange rate, relegated the inflation "problem" to one dictated by purely domestic considerations. After all, an earlier generation experienced inflation that was high and volatile, and associated with stagnation, the legacy of two large oil price shocks and exacerbated by the limited exchange rate flexibility of the Bretton Woods era. A still earlier era saw the golden 'fetters' of the Gold Standard that produced frequent bouts of deflation (e.g., see Eichengreen 1992). Once again, global factors played a role in the transmission of inflation shocks across countries. Eventually, every one of these regimes became associated, at least in the minds of some policy makers, with unsatisfactory economic 
performance. ${ }^{3}$ Policy regimes, deemed to have disappointed, were abandoned and new ones were ushered in that promised success by correcting past policy failures. Bordo and Siklos $(2016,2018)$ explore in detail the adoption and evolution of monetary policy regimes over time.

More than two decades after the mantra of low and stable inflation spread globally, the GFC and the Great Recession that followed it especially in the advanced economies, renewed the debate about the wisdom of sticking with the existing monetary policy regime. However, unlike the debates of the past several decades, the problem now centers on inflation being too low. Together, all these developments reflect continued interest in trying to understand the dynamics of the relationship between inflation, inflation expectations, and broader economic performance.

Following a brief historical recap of the recent literature on inflation dynamics, the role of inflation expectations, and the influence of globalization, the paper examines inflation and inflation expectations performance in 29 countries for over three decades until 2018. The data covers both advanced (AE) and emerging market economies (EME). The paper then examines the impact of global inflation and inflation expectations on individual and regional economies' inflation performance.

Time series modelling is also used to explore the extent to which structural breaks in the inflation process, and their timing, is common across countries, and whether this reflects the importance of 'global forces'. I also explore whether crisis conditions have influenced crosscountry 'interdependence' in inflation. The global component driving domestic inflation is seen as the result of spillover effects that may be exacerbated or alleviated by structural changes in the inflation process.

Briefly, three conclusions stand out. Global inflation impacts inflation in both AE and EME but the impact is far more heterogeneous than existing narratives would lead us to believe. Indeed, one's interpretation of global influences on domestic inflation differs depending on whether poorly performing economies in inflation terms are considered as opposed to the standard practice of examining mean inflation performance. The focus on how observed inflation impacts individual economies ignores that inflation expectations, including a global version of this variable, also plays a critical role in inflation dynamics. Finally, there are significant spillovers in inflation between AE and EME, but these too are sensitive according to relative inflation performance.

The rest of the paper is organized as follows. The next section provides brief literature survey. The data and methodology are outlined in section 3 prior to a description of the results in section 4 . The paper concludes in section 5 with a summary and a few policy conclusions are drawn.

\footnotetext{
3 Japan remains a 'poster child' for the view that deflation and stagnation are linked to each other. See Burdekin and Siklos (2004), Siklos (2020), and references therein.
} 


\section{SIKLOS Inflation Dynamics}

\section{The Global Factor in Inflation: Recent Views}

The need to understand not only the dynamics of inflation but the nexus between inflationary developments and inflation expectations is critical if existing models of inflation are to remain useful to policy makers. It is not difficult to find expressions of the need to better understand how these two variables co-vary, or their dynamic relationship. For example, former FOMC Chair Bernanke (2007), argues that "...we must understand better the historical variation in inflation expectations, the effect of this variation on actual inflation...". Sargent (1999), 2011 Nobel Laureate, argues that once the public comes to believe that the net benefits of higher inflation become negative there will be a demand for a lower inflation rate. Hence, a connection exists between inflation and monetary policy regimes. Presumably, when policy regimes change, one might expect to see a structural break in the inflation process. However, compared to other aspects of the study of inflation dynamics, there are relatively fewer studies of breaks in the inflation process. A few exceptions include Belkhonja and Mootami (2016) who estimate inflation models over a long sample and highlight the role of the 1970s oil price shocks and the GFC. Altansukh et. al. (2018) explore breaks not only in mean inflation rates in OECD economies but find clusters of breaks in the variances. They also report significant impact of global factors on domestic inflation. Zhang and He (2016), who focus on inflation in China whose role, as we shall see, has sparked some of the recent debates on global inflation performance, conclude that 1994 marks a point of structural change in the inflation process. That year marks the introduction of significant economic reforms to liberalize the economy. Eo (2015) finds that breaks are variable and time sensitive, at least in the US since the 1950s. Some parallels to this finding are reported below.

A considerable challenge in this area is overcoming what may be surprising to many, namely that we have yet to develop a good understanding of the behavior of inflation expectations. Since the 1990s a growing number of central banks were mandated to achieve price stability and often this was explicitly specified via a numerical inflation target (e.g., see Siklos 2017).

While the GFC led a reallocation of tasks many central banks in favor of evincing a concern for financial stability, debate over the future course of inflation (or deflation) remain at the forefront of central bank concerns. This is true, in spite of mounting evidence that global economic slack persists, primarily in the industrial world. ${ }^{4}$ Soon after the GFC erupted, there were fears that global fiscal stimulus measures would generate excessive inflation or, at least, the de-stabilizing inflationary impulses that characterized pre-central bank independence stop-

\footnotetext{
4 Apart from the usual challenges in measuring the level of slack in the economy is uncertainty over whether allowances should be made for a significant structural shift in potential economic activity, not to mention the distribution of slack as between domestic and global sources. See, inter alia, Borio and Filardo (2006), and IMF (2013).
} 
go type monetary policy regimes (e.g., see Goodfriend and King 2013). These factors, taken together, can easily lead to conditions that can de-anchor inflationary expectations.

A mere five years after the GFC, the IMF (2013) concluded that inflation is "The Dog That Didn't Bark", largely thanks to the benefits of central bank independence and an improved capacity of the part of policy makers to control an economy's inflationary impulses. However, as central banks have increasingly been called upon to support fiscal policy and finance sovereign debt, considered unsustainable by some (e.g., Schoder 2013), the potential collateral damage is that central banks are losing their independence. Even if inflation is not imminent, the de-anchoring of inflation expectations, given its persistence properties (e.g., Fuhrer 2009), can exacerbate observed inflation rates if the central bank finds it difficult to modify the stance of monetary policy. Others have argued that we can ignore while not turning a blind eye to inflation and shift the weight of policies almost exclusively in the direction of attaining higher economic growth (e.g., Brittan 2013, Wadhwani 2013).

It is worth noting that IMF (2013) examines only the inflation record in advanced economies. Underlying economic uncertainty is ignored, as are exchange rate regime choices and central bank transparency. The remarkable stability of inflation over the past few years may also be a reflection of the increasing reliance, if not coordination, of inflation expectations with those of the central bank. Morris and Shin's (2002) analysis warns us of the theoretical possibility that this can happen. Even if some of the ingredients of their model are considered implausible (Svensson 2002), a potential source of the de-anchoring of inflation expectations is the loss of credibility in central banks' forecasting performance, possibly reflected in a rise in forecasters' disagreement vis-à-vis the forward-looking scenarios of the central bank (e.g., Siklos 2013, Bordo and Siklos 2019).

Rules-based policies, including the Taylor rule which represents the embodiment of modern monetary policy making, ensure that shocks that lead inflation and economic output to deviate from their respective targets or capacity levels can eventually (and optimally) be eliminated via manipulation of an instrument of monetary policy, ordinarily an interest rate. However, economic 'headwinds' in unusual times may well justify a looser policy for an extended period. As a consequence, a tightening would be delayed only after inflation returns to target. Policymaking under these conditions requires flexibility of a different type from the 'constrained discretion' that defines central bank behavior in normal times. ${ }^{5}$ The implication then is that central banks may be required to act 'irresponsibly' for a time until normal economic

\footnotetext{
${ }^{5}$ To illustrate, the Bank of Canada's approach to monetary policy reacting to headwinds (or tailwinds) is explained in its July 2011 Monetary Policy Report, p. 28-29. Headwinds include continued currency appreciation; tailwinds stem from the effects of financial shocks. This description serves to partly explain the Bank of Canada's stance in crisis times. Presumably, these phenomena are also applicable to other economies.
} 


\section{SIKLOS Inflation Dynamics}

conditions return. ${ }^{6}$ Why these same central banks did not act in a way that would obviate the need to be irresponsible, thereby threatening their reputation, is never properly explained.

If the prospect of future inflation above some target pre-occupies some central banks others are also concerned about a renewed threat of deflation. Although there is little evidence that mild deflation is economically harmful ${ }^{7}$ some central banks are determined to avoid prolonged deflations at all costs.

Until the GFC, the primary source of concern over the global element in inflation came from evidence that emerged linking the rapid growth of the Chinese economy to a decline in inflation rates worldwide. Indeed, such was the concern that China's rapid development would drive prices down globally that it sparked worries about the spread of deflation. However, for reasons that are beyond the scope of this paper, narratives about deflation were by then also wrapped up with developments in Japan where very low inflation and deflation gripped that economy for over a decade. Bernanke (2002), at the time a member of the Board of Governors of the Fed, publicly declared that the Fed would stand against deflation thanks to the "...structural stability of the U.S. economy..." and the Fed's determination to "...take whatever means necessary to prevent significant deflation...". Never mind that the relationship between deflation and economic performance was largely biased by the experience of the Great Depression of the 1930s and that China's own deflation in the 1990s may have been of the 'good' variety (e.g., see Burdekin and Siklos (2004), Siklos and Zhang (2010), Borio and Filardo (2007), and Borio, Erdem, Filardo and Hofmann (2015)).

The emergence of China as a great economic power on the global stage generated a flurry of studies of China's contribution to individual countries' inflation rates. For example, Eickmeier and Kühnlenz (2018) conclude that China's impact on global inflation is often less than $10 \%$ while Zhang and $\mathrm{He}$ (2016) remind us that, even if China's growing economic might has global impact, shocks from the rest of the world also effect China's economy, especially since the mid-1990s. The bottom line, as Bailliu and Blagrave (2010) and Chen and Siklos (2020) point out, is that China's economy belongs in the group of globally systemically important economies even if the country belongs to the group of EME.

The initial focus on China's role in global inflation and economic activity was soon replaced by the broader issue of how rising globalization in both trade and finance (e.g., see Figure 1) may have contributed to the fall in inflation over the past decade. ${ }^{8}$ As the quote at the beginning

\footnotetext{
${ }^{6}$ This view is attributed to Woodford (2012) who argues that, where relevant, policy rates may be required to stay at the zero lower bound beyond the time suggested by the Taylor rule.

${ }^{7}$ The fear of deflation is dominated by the experience of the Great Depression of the late 1920s and early 1930s. For relevant empirical evidence that explores the consequences of different episodes of deflation, see Burdekin and Siklos (2004), and Borio and Filardo (2004).

${ }^{8}$ Prior to the arrival of China on the scene studies of the determinants of inflation did not entirely ignore 'global forces'. Indeed, in small open economies, worries over external influences on domestic inflation
} 
of the paper suggests, even central bankers can fall prey to logical inconsistencies or, rather, mis-communication by confusing relative and absolute price changes. Moreover, exchange rates and monetary policy strategies ought to play a role as bulwarks against external shocks (Bohl, Mayes, and Siklos 2011). That said, global factors, even in a world where monetary policy is sovereign and countries float their exchange rate to differing degrees (Ilzetzki, Reinhart and Rogoff 2019), can still potentially drive domestic inflation rates. ${ }^{9}$ Hence, interest in the notion that there is a global element in inflation dynamics has not waned in the literature that has investigated various puzzles in it behavior.

No consensus has emerged yet on the question of how important global factors are in explaining relatively low inflation rates in recent years. Nevertheless, there is growing acceptance of the view that a global element can play a role in inflation dynamics even if evidence from its importance ranges from marginal (e.g., see Brouillette and Savoie-Chabot 2017) to large (e.g., Ciccarelli and Mojon 2010). Part of difficulty is the recognition that the role of global factors has changed over time (e.g., Forbes 2019). Moreover, it may be the case that some components that are important drivers of inflation are more cyclically sensitive than others (e.g., services; Stock and Watson 2019). Another challenge stems from the possibility that the pass-through effects of global factors on domestic inflation rates may well be dictated by differences in economic circumstances faced by advanced versus emerging market economies (e.g., Parker 2018), although there is evidence that inflation rates are looking more alike around the world in recent years (e.g., Ha, Kose, and Lieselotte Ohnsonge 2019).

An element that is curiously missing from much of the literature is the role played by the relationship between observed and expected inflation. The former is, by far, the focus of interest in the studies cited above. In contrast, the role of expectations generally plays a critical role in country-specific studies. Yet, how well expectations are anchored is an issue that cannot be adequately addressed via studies that rely on observed inflation data alone. Mehrotra and Yetman (2018) propose a more realistic method to investigate the long-run anchoring of inflation expectations. However, based on a sample for a large number of countries, they cannot reach a definitive conclusion about the extent to which professional forecasts are informative about anchoring. Clark and Davig (2009), relying on US data, find that shocks to inflation expectations are transitory. Nevertheless, these expectations are found to be crucial in driving observed inflation.

were often evaluated in terms of the impact of import prices or exchange rate effects in domestic inflation. Examples include is Dungey and Pitchford (2000) for Australia, and an even earlier example is Fried (1973) for Canada.

9 As is well-known, an important distinction is the one between headline and core inflation rates. Data limitations limit the study of global factors on core inflation beyond a handful of economies. However, Bhatnagar et. al. (2017) conclude that core inflation is not influenced by global factors. Altansukh et. al. (2017) find that energy shocks from abroad play an important role in driving a global inflation factor. The authors also focus on the behavior of core inflation co-movements among OECD economies. 
A major difficulty, of course, is spotty data availability beyond advanced economies. Nevertheless, Feldkircher and Siklos (2019), in a study that covers over 40 AE and EME, find that commodity price changes, notably oil prices, are likely candidates for the de-anchoring of expectations. More generally, inflation expectations are also found to contain a global component although whether these are the same as the ones driving observed inflation remains unclear (e.g., see Siklos 2010). Indeed, even in emerging markets, domestic longer-run inflation expectations, themselves linked to the policy regime in place, drive domestic inflation (Bems et. al. 2018). Hence, it is not surprising that central bankers have tended to zero in on food and energy prices as a major source of concern in setting and communicating the stance of monetary policy even if, in doing so, they have created some confusion, as noted above.

\section{Data}

Quarterly data since 1980 were obtained from sources provided in Bordo and Siklos (2019). ${ }^{10}$ Nevertheless, due to data limitations for several of the emerging market economies many of the tests reported below rely on samples from 1995.1-2018.3 (95 observations) or 1998.1-2017.4 (80 observations), depending on whether observed or expected inflation data, respectively, are used. ${ }^{11}$ Expected inflation is defined as the one year ahead inflation forecast a time $t$. Forecasts are fixed horizon forecasts (see Siklos 2013). A total of 29 economies are included, consisting of $12 \mathrm{AE}$ and $17 \mathrm{EME}$. In what follows, each economy in the data set is identified by its two letter ISO code. Table 1 provides a key.

Table 1 provides some summary statistics. Notable is the wide range of inflationary experiences with large gaps between the highest and lowest inflation rates. This is especially true of emerging market economies. Of course, reflected in the large standard deviations of inflation. It is worth remembering, as first seen in Figure 1, that sample averages mask the downward trend in inflation, and inflation variability, in both AE and EME since the 1980s. Moreover, a focus solely on the mean inflation experience also implies missing some potentially interesting dynamics contained in the overall distribution of inflation performance. Table 1 also provides summary statistics for the two inflation forecasts that are combined in some of the tests reported below. It is worth pointing out that Consensus and WEO forecasts ${ }^{12}$ are generally comparable except when mean inflation rates are high, that is, for EME. Finally,

10 The details are contained in a data appendix available online from https://data.nber.org/dataappendix/w26342/.

11 For example, I excluded periods of very high inflation or hyperinflation during the 1980s and early 1990s which plagued several EME especially in the data set (e.g., for BR, PL RU, IL, MX, PE, TR)

${ }^{12}$ These are the forecasts published twice a year by the International Monetary Fund in its World Economic Outlook (WEO). 
Table 1 Summary Statistics: Inflation and Inflation Expectations

Observed Inflation

\begin{tabular}{|c|c|c|c|c|c|c|c|c|c|c|c|c|c|c|c|c|c|c|c|c|c|c|c|c|c|c|c|c|c|}
\hline & AR & $\mathrm{AU}$ & BR & CA & CL & $\mathrm{CN}$ & $\mathrm{CO}$ & $\mathrm{CZ}$ & EZ & GB & $\mathrm{HU}$ & ID & IL & IN & JP & KR & MX & MY & $\mathrm{NO}$ & $\mathrm{NZ}$ & PE & $\mathrm{PH}$ & PL & RU & SE & TH & TR & US & $\mathrm{ZA}$ \\
\hline ear & 12 & 55 & .13 & 1.86 & 3.79 & 2.83 & 7.81 & 3.40 & 1.71 & 2.03 & 7.43 & 99 & 2.98 & 6.91 & 0.15 & 2.94 & 8.86 & 2.53 & 2.10 & 2.06 & 3.91 & 54 & 5.49 & 6.31 & 1.16 & .74 & 8.00 & .23 & 09 \\
\hline dian & 9.77 & 2.47 & 6.21 & 1.83 & 3.50 & 2.03 & 6.02 & 2.43 & 1.90 & 1.94 & 36 & 47 & 1.8 & 32 & .10 & 2.69 & 4.74 & 2.32 & 2.17 & 1.96 & 3.20 & 4.08 & 3.42 & 1.35 & .06 & .47 & 0.28 & 2.20 & .92 \\
\hline $\operatorname{Max}$ & 40.31 & 6.08 & 26.50 & 4.48 & 9.30 & 22.60 & 21.79 & 13.25 & 3.77 & 4.81 & 30.38 & 58.57 & 13.33 & 17.86 & 3.60 & 8.93 & 48.70 & 8.41 & 4.70 & 5.30 & 12.90 & 10.28 & 32.79 & 16.82 & 4.28 & 10.29 & 73.04 & \begin{tabular}{|l|}
5.30 \\
\end{tabular} & 13.43 \\
\hline Minimum & \begin{tabular}{|l|} 
\\
\end{tabular} & -0.33 & 1.82 & -0.86 & -3.30 & -1.87 & 1.85 & -0.39 & -0.38 & -0.03 & -1.06 & -0.60 & -2.52 & 0.46 & -2.21 & 0.56 & 2.27 & -2.29 & -1.43 & -0.50 & -1.36 & -0.06 & -1.21 & 25 & -1.42 & .78 & 4.34 & .62 & 0.44 \\
\hline Std. Dev. & 10.36 & 1.29 & 4.28 & 0.81 & 2.31 & 3.96 & 5.87 & 3.13 & 0.86 & 1.01 & 7.20 & \begin{tabular}{|l|} 
\\
\end{tabular} & 3.51 & 3.33 & 1.02 & 1.65 & 9.75 & 1.44 & 0.99 & 1.27 & 3.04 & 2.31 & 7.00 & 19.83 & 1.17 & 2.51 & 27.13 & 1.13 & 2.51 \\
\hline pservati & 83 & 95 & 93 & 95 & 95 & 95 & 95 & 95 & 95 & 95 & 95 & 95 & 95 & 95 & 95 & 95 & 95 & 95 & 95 & 95 & 95 & 95 & 95 & 90 & 95 & 95 & 95 & 95 & 95 \\
\hline
\end{tabular}

\section{Combined Inflation Forecasts}

\begin{tabular}{|l|c|c|c|c|c|c|c|c|c|c|c|c|c|c|c|c|c|c|c|c|c|c|c|c|c|c|c|c|c|}
\hline & AR & AU & BR & CA & CL & CN & CO & CZ & EZ & GB & HU & ID & IL & IN & JP & KR & MX & MY & NO & NZ & PE & PH & PL & RU & SE & TH & TR & US & ZA \\
\hline Mean & 10.88 & 2.54 & 6.70 & 1.91 & 3.51 & 2.43 & 8.23 & 3.67 & 1.72 & 2.43 & 7.40 & 8.23 & 1.92 & 7.01 & 0.29 & 2.92 & 7.75 & 2.53 & 2.02 & 2.19 & 3.22 & 4.33 & 6.42 & 7.73 & 1.65 & 2.62 & 8.20 & 2.27 & 6.37 \\
\hline Median & 10.75 & 2.54 & 5.87 & 1.91 & 3.31 & 2.12 & 5.43 & 2.76 & 1.89 & 2.47 & 4.93 & 6.65 & 1.90 & 6.53 & 0.28 & 2.73 & 4.35 & 2.45 & 2.03 & 2.16 & 2.71 & 4.08 & 3.18 & 7.93 & 1.70 & 2.75 & 7.80 & 2.29 & 6.04 \\
\hline Maximum & 37.34 & 3.96 & 42.06 & 2.81 & 5.29 & 11.10 & 22.51 & 9.34 & 2.70 & 3.93 & 24.97 & 28.72 & 4.26 & 13.73 & 2.41 & 7.96 & 27.62 & 4.67 & 2.95 & 4.23 & 7.71 & 7.13 & 28.21 & 12.31 & 2.58 & 4.29 & 11.32 & 3.42 & 11.24 \\
\hline Minimum & -0.13 & 1.51 & -3.23 & 0.86 & 2.70 & -0.47 & 2.50 & 1.22 & 0.51 & 0.68 & 1.20 & 3.34 & 0.14 & 3.97 & -1.04 & 0.91 & 2.93 & 0.86 & 1.12 & 0.68 & 2.23 & 2.03 & 0.56 & 2.10 & 0.53 & 0.30 & 6.23 & 0.41 & 3.85 \\
\hline Observations & 95.00 & 95.00 & 88.00 & 95.00 & 80.00 & 91.00 & 92.00 & 88.00 & 75.00 & 95.00 & 92.00 & 95.00 & 68.00 & 95.00 & 95.00 & 95.00 & 95.00 & 92.00 & 68.00 & 80.00 & 80.00 & 52.00 & 92.00 & 51.00 & 68.00 & 52.00 & 51.00 & 95.00 & 95.00 \\
\hline
\end{tabular}

Note: combined inflation forecasts are the mean of Consensus and WEO one year ahead inflation forecasts. Observed inflation is the annual rate of change in CPI inflation. Data are from Bordo and Siklos (2019). Country codes (ISO ) are as follows: AR (Argentina), AU (Australia), BR (Brazil), CA (Canada), CL (Chile), CN (China), CO (Colombia), CZ (Czech R.), EZ (Eurozone), GB (Great Britain), HU (Hungary), ID (Indonesia), IL (Israel), IN (India), JP (Japan), KR (Korea), MX (Mexico), MY (Malaysia), NO (Norway), NZ (New Zealand), PE (Peru), PH (Philippines), PL (Poland), RU (Russia), SE (Sweden), TH (Thailand), TR (Turkey), US (United States), ZA (South Africa). 


\section{SIKLOS Inflation Dynamics}

standard deviations for most forecasts are smaller, occasionally considerably smaller (e.g., in $\mathrm{AU}, \mathrm{BR}, \mathrm{ID}$, and RU) than their counterparts for observed inflation.

Next, we turn to estimation of the global factor. I follow others (e.g., Forbes 2019, Bordo and Siklos 2019) by extracting the first principal component of inflation. Clearly, other methods can be used but one advantage if this approach, other than its wide applicability in obtaining a common component of several series, is that it is easy to evaluate the degree to which each economy's inflation rate has in common with the other inflation rates in the factor model Furthermore, this approach is relatively parsimonious which is also an advantage when the number of observations is relatively modest. ${ }^{13}$

Nevertheless, I consider two modifications to traditional factor model estimation. First, in order to ascertain how sensitive subsequent test results are to the construction of global series, I estimate a global inflation series not only based on the data for all 29 economies but also separate estimates that rely on data only from AE and EME, respectively. Second, and arguably more importantly, time-varying estimates of the global factor are estimated using by extracting the factor scores, that is, the series that proxies global inflation, from factor models estimated in a rolling manner. This is accomplished as follows. Each factor model consists of inflation, mean Consensus and WEO inflation forecasts, and WEO forecasts for all the economies in the sample, or AE and EME separately. I estimate the same factor models for samples that range from 8 to 10 years in length in a rolling manner. Samples begin in 1992 for AE and 1998 for EME and all economies together. ${ }^{14}$ The sample is rolled ahead one to two years at a time. ${ }^{15}$ This produces a series of overlapping samples. ${ }^{16}$ The estimated factor scores are averaged when samples overlap to produce a unique factor estimate that is time-varying. ${ }^{17}$

Figure 2 respectively compares observed inflation for AE and EME with their 'global' counterparts estimated via time-varying factor models as described above. ${ }^{18}$ There are several interesting features to note from the plots. The decline in observed and forecasted inflation from

\footnotetext{
${ }^{13}$ For example, loadings (i.e., akin to regression weights) the relative importance of each for the $1^{\text {st }}$ principal component for advanced economies explain between $60 \%$ and $81 \%$ of the variation in inflation. This figure drops for all economies in the dataset to a range of $37 \%$ to $49 \%$. Communality (i.e., the percent of the variance each individual inflation series shares with the other variables in the factor model) is very high for both AE and EME and ranges from a low of $64 \%$ to a high of $99 \%$.

${ }^{14}$ Hence, for example, the first sample for AE is 1992-1999.

${ }^{15}$ Two-year rolling seems adequate for $\mathrm{AE}$ and one year rolls are preferable for EME not only because the sample is shorter but also, as noted earlier, inflation rate levels have changed considerably more in that part of the world than in AE.

${ }^{16}$ The samples are 5 years long for EME and 6 years for the AE. The slightly longer span for AE is due to the smaller volatility of inflation among these economies than in EME (see Table 1).

${ }^{17}$ And we can obtain a range of estimates of the global factor (i.e., maximum, minimum, median).

${ }^{18}$ Estimates for all economies in the sample are relegated to the appendix.
} 
Figure 2. Estimates of Global Inflation: AE and EME
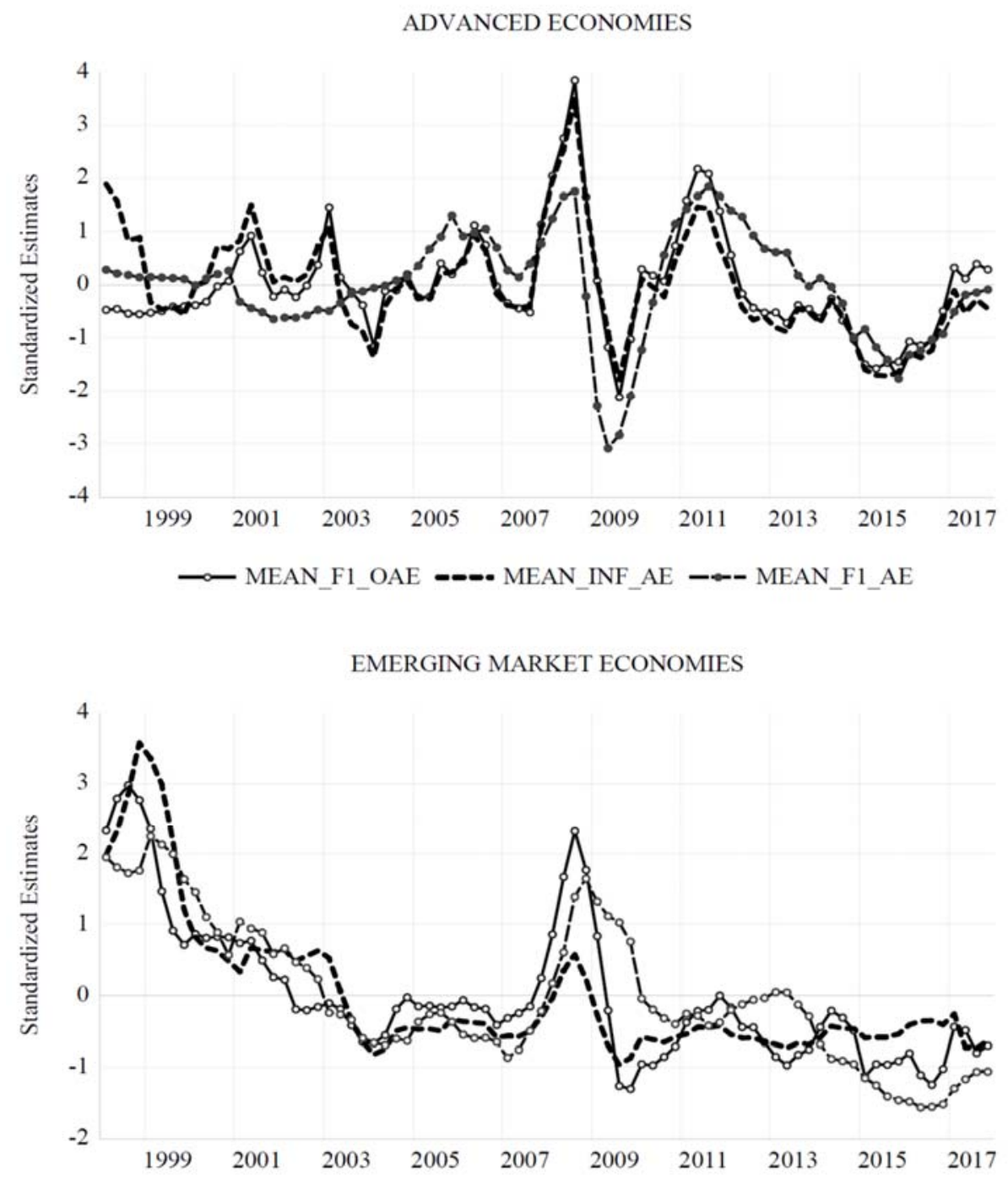

$\longrightarrow$ MEAN_F1_OEME $-\infty$ MEAN_INF_EME $-\infty-$ MEAN_F1_EME

Note: MEAN refers to the (unweighted) inflation rate for advanced (AE) and emerging market economies (EME). "O" refers to estimates based on observed CPI inflation as defined in the text. F1 refers to the $1^{\text {st }}$ principal component of inflation. All factor scores are time-varying in the manner described in the min body of the paper 
the late 1990s to the mid-2000s in EME is clearly visible. Second, both AE and EME experience a surge in inflation, both global and domestic varieties, just before the GFC. A reversal then takes place very quickly, again in both parts of the globe. However, the rise in observed inflation is considerably smaller in EME than in AE, at least relative to estimates based on the combination of forecasts or WEO forecasts alone. Next, there is a secondary surge in inflation in AE but not in EME after the GFC. Perhaps this reflects the initial impact of unconventional monetary policies in the large AE economies in the sample (i.e., US, UK, and, subsequently, the EZ). Finally, the decline in various indicators of observed and global inflation after 2011 is also visible and the phenomenon is shared by both AE and EME.

In what follows we use all three estimates of global inflation (observed, combination of forecasts, WEO forecasts) to explain inflation developments in the individual economies in the sample as well as for the group of AE and EME. However, to conserve space, not all the results can be discussed. The results discussed below emphasize the role of global (i.e., AE and EME together) inflation and inflation expectations on domestic inflation rates.

\section{Methodology and Empirical Results}

Empirical testing proceeds in two steps. The first phase consists in asking about the timing of structural breaks in a model of inflation where explicit allowance is made for a global factor to influence domestic inflation, in addition to other determinants. The literature generally takes two positions when considering the possibility of statistical breaks in the data. These can be accounted for based on some widely acknowledged event deemed exogenous. In this case the GFC represents an obvious candidate. Alternatively, it has been suggested that a statistical metric ought to be employed to select a breakpoint, that is, the identification of breaks ought to be data-determined. Both sides of the debate have strong points in their favor. Those who advocate a historical approach argue that events, and their dating, speak for themselves and can also be used to gauge the relative importance of shocks that cannot easily be accommodated or measured by available time series. Researchers who favor a data-driven approach point out that even when events can be dated via historical analysis the impact on the time series of interest need not occur simultaneously with an event dated via observers' judgment. Consider the GFC. Although many chronologies have been developed, the beginning and end of the GFC differ depending on the author. For example, the St. Louis Fed's chronology ${ }^{19}$ begins in February 2007 while the New York Fed's chronology ${ }^{20}$ begins in June of the same year. If we also

\footnotetext{
${ }^{19}$ See https://fraser.stlouisfed.org/timeline/financial-crisis.

${ }^{20}$ See https://www.newyorkfed.org/research/global economy/policyresponses.html. The Fed's chronology also provides separate US and international timelines.
} 
include the Eurozone's sovereign debt crisis ${ }^{21}$ there is also the potential of overlap with the GFC, at least at the start. Yet another illustration is the adoption of a new monetary policy regime such as inflation targeting. Often these regimes are announced well ahead of their formal adoption or there may be a transitional period before the regime is fully implemented (e.g., see Bordo and Siklos 2018).

Accordingly, in what follows, I examine the impact of statistical breaks on inflation in the individual economies in our sample as well as in the advanced and emerging market regions as a whole by allowing breaks to be both endogenously and exogenously determined. In the case of exogenously imposed breaks I restrict the analysis to the period of the GFC since this clearly is the most obvious candidate for a shift in the inflation process. The dates proposed by Dominguez, Hashimoto, and Ito (2012) are used. ${ }^{22}$ In the case of endogenously estimated breaks I follow the Bai-Perron (1998) multiple break-point test for the data from individual economies (also see Bai and Perron 2003a, 2003b), and Bai (2010) for the multiple break point test in a panel setting. To conserve space the panel consists of inflation for the AE and EME regions as opposed to the individual economies in the dataset. Furthermore, given the length of the sample, I restrict the number of breaks to a maximum of two and consider only innovation outliers, that is, a break that is deemed to have a potentially permanent impact on inflation. With the exception of one additional test (see below) breaks that interact with one or more series are omitted to conserve degrees of freedom. These assumptions can, of course, be relaxed but it is unclear that there are significant net benefits from the added model complexity. These complications are left for future work. Finally, Newey-West standard errors are estimated, and breaks that are statistically significant at the $1 \%$ only are considered while trimming at either end of the sample of $\pm 5 \%$ is imposed. ${ }^{23}$ To further limit the possibility of minor breaks to be estimated along with larger (and more statistically significant breaks) the sequential version of the null hypothesis is used. In other words, the null of one statistically significant break must be rejected before a second break is permitted. ${ }^{24}$

The model of inflation estimated in the no-break case is written as follows:

\footnotetext{
${ }^{21}$ The ECB used to publish a timeline comparable to the ones in the previous two footnotes but this has been removed. See Siklos (2017) and https://www.bbc.com/news/business-13856580 for an example of a chronology of the Eurozone crisis.

${ }^{22}$ Their analysis does not identify a GFC period for the Eurozone. Instead, I took the dates for Germany, Italy, France, and Spain, the Eurozone's largest economies, and dated the start of the GFC as the earliest and latest dates in all four countries.

${ }^{23}$ This effectively implies that breaks cannot be estimated for 1995 or 1998 and 2017 or 2018, depending on the particular sample in question.

${ }^{24}$ That is, if there are potentially $\mathrm{K}$ breaks, the null of $\mathrm{K}+1$ is tested against the alternative of $\mathrm{K}$ breaks.
} 
SIKLOS Inflation Dynamics

$$
\pi_{t}=\alpha_{0}+\alpha_{1} E_{t} \pi_{t+1}+\alpha_{2} E_{t} g_{t+1}+\alpha_{3} g_{t-1}+\alpha_{4} i_{t-1}+\alpha_{5} \varepsilon_{t-1}+\alpha_{6} c_{t-1}+\alpha_{7} \pi_{t-1}^{G}+\eta_{t}
$$

where $\pi$ is the annual inflation rate estimated as 100 times of the fourth order log difference in the CPI, $E_{t} \pi_{t+l}$ is the one year ahead inflation forecast as the proxy for inflation expectations, $E_{t} g_{t+1}$ is the one year ahead forecast of real GDP growth, $g$ is observed real GDP growth, $i$ is the central bank policy rate, $\varepsilon$ is the rate of change in the real effective exchange rate, $c$ is the growth rate of commodity prices, and $\pi^{G}$ is the global inflation proxy obtained from the factor models described earlier. Recall that one global inflation proxy relies on observed data while the second proxy relies on forecast combinations. Data sources were provided earlier (i.e., see Bordo and Siklos 2019). Resort to rates of change in real GDP, commodity prices and real exchange rates is standard though it should be noted that studies of this kind may rely on deviations from some equilibrium where the latter, unobserved, is estimated via one of several filters (e.g., Hodrick-Prescott). I chose to rely on rates of change for selected variables for ease of exposition as well as based on the extensive testing of various filters discussed in Bordo and Siklos (2019).

Equation (1) is a typical model of inflation with a measure of economic slack (i.e., $g$ ), and expected inflation appearing in most versions of a Phillips curve equation. Similarly, estimates of the determinants of inflation for small open economies might include a real exchange rate variable. Less frequently encountered are models that incorporate commodity prices or the global inflation proxy (e.g., see Siklos 2020). I did conduct some experimentation with lags as well as incorporating other potential candidates as determinants such as credit growth, housing price inflation, and the rate of change in equity prices, but these did not fundamentally change the results or there were some gaps in the data which did not allow me to include all 29 economies in some of the tests reported below. ${ }^{25}$ Nevertheless, I return below to the question of inflation determinants beyond the ones shown in equation (1).

Table 2 lists, for each economy in the sample, the dates selected by the Bai-Perron or Bai tests for multiple endogenously estimated breaks. The Table is structured so that $\mathrm{AE}$ are shown first followed by EME. Conditional on (1) most economies experience two significant breaks in the inflation process. A very few shows signs of a single break (e.g., CL based on the global inflation forecast factor for $\mathrm{AE}$ ), or none (e.g., $\mathrm{CN}$ based on the global inflation forecast factor for all economies).

Although the test provides a precise date for each break the coefficient is, of course, measured imprecisely. Hence, as a rule of thumb, I consider a change in the inflation process

\footnotetext{
${ }^{25}$ For example, private non-bank financial assets, a common indicator of credit growth is available for only 21 of the 29 economies in the dataset.
} 
Table 2 Structural Breaks in Inflation: Endogenous and Exogenous

\begin{tabular}{|c|c|c|c|c|c|}
\hline \multirow[b]{2}{*}{ Economy } & \multicolumn{2}{|c|}{ Observed Inflation } & \multicolumn{2}{|c|}{ Inflation Forecasts } & \multirow[b]{2}{*}{ GFC } \\
\hline & All & $\mathrm{AE}$ & All & $\mathrm{AE}$ & \\
\hline AU & $2003.2,2012.1$ & $2001.4,2012.1$ & $2006.2,2012.1$ & $2001.4,2012.1$ & $2008.3-2009.2$ \\
\hline $\mathrm{CA}$ & $2003.2,2012.2$ & 1999.2 & $2004.2,2012.2$ & $2003.2,2012.4$ & 2008.3-2009.2 \\
\hline $\mathrm{CZ}$ & $2007.4,2012.1$ & $2003.1,2007.4$ & $2007.4,2013.1$ & 2007.4 & $2008.4-2009.1$ \\
\hline EZ & $2007.4,2013.1$ & $2002.4,2013.1$ & $2007.4,2013.1$ & $2011.4,2015.3$ & $2008.1-2009.3$ \\
\hline GB & $2005.2,2012.2$ & $1999.1,2004.2$ & $2007.3,2012.3$ & $2001.4,2008.2$ & $2008.2-2009.2$ \\
\hline $\mathrm{IL}$ & $2013.3,2009.4$ & $2003.3,2011.3$ & $2003.4,2009.1$ & $2003.3,2007.4$ & $2009.1-2009.4$ \\
\hline JP & NONE & $2001.1,2013.3$ & $2010.1,2013.3$ & $2002.1,2013.3$ & $2007.2-2009.1$ \\
\hline KR & $2010.1,2014.4$ & $2010.2,2016.1$ & $2009.3,2015.1$ & $2009.1,2014.2$ & 2007.4-2009.1 \\
\hline $\mathrm{NO}$ & $2004.2,2011.2$ & $2004.2,2011.1$ & $2004.2,2008.2$ & $2004.2,2008.4$ & $\underline{2008.4-2009.2}$ \\
\hline NZ & $2006.3,2011.4$ & $2010.2,2015.1$ & $2008.3,2011.4$ & $2012.3,2015.1$ & $2008.4-2009.2$ \\
\hline $\mathrm{SE}$ & $2007.1,2011.4$ & $2009.4,2014.1$ & $2008.4,2012.3$ & $2007.4,2012.4$ & $2007.4-2009.1$ \\
\hline US & $2009.4,2015.4$ & $2009.4,2015.1$ & $2006.4,2012.1$ & $2009.4,2015.1$ & $2008.3-2009.2$ \\
\hline AR & $2005.1,2015.2$ & $2005.1,2017.4$ & $2005.1,2014.2$ & $2005.1,2015.2$ & $2007.4-2009.1$ \\
\hline $\mathrm{BR}$ & $2001.4,2013.4$ & $2000.4,2015.1$ & $2007.3,2015.2$ & $2001.2,2015.1$ & $2008.3-2009.1$ \\
\hline $\mathrm{CL}$ & $2007.3,2017.4$ & $2003.2,2014.2$ & $2010.4,2015.2$ & 2013.1 & $2008.2-2009.1$ \\
\hline $\mathrm{CN}$ & $2004.4,2012.2$ & $2006.3,2011.2$ & NONE & $2008.3,2012.3$ & $\underline{2008.4-2009.1}$ \\
\hline $\mathrm{CO}$ & $2001.1,2012.1$ & $2000.2,2011.2$ & $2003.4,2014.1$ & $2001.1,2011.2$ & 2008.4-2009.1 \\
\hline $\mathrm{HU}$ & $2008.1,2012.1$ & $2007.4,2015.2$ & NONE & $2007.4,2009.4$ & 2008.4-2009.1 \\
\hline ID & $2007.3,2010.3$ & $2007.3,2010.3$ & $2003.1,2010.3$ & $2007.3,2011.2$ & $2008.3-2008.4$ \\
\hline IN & $2001.3,2010.3$ & $2000.1,2010.3$ & $2011.1,2014.1$ & $2001.2,2010.3$ & $\underline{2008.4-2009.1}$ \\
\hline MX & 2003.22013 .4 & $2002.2,2014.2$ & $2008.2,2010.4$ & $2008.2,2011.3$ & 2008.3-2009.1 \\
\hline MY & $2004.4,2009.3$ & $1999.2,2009.3$ & $2006.3,2011.1$ & $2003.2,2011.3$ & $2008.3-2009.1$ \\
\hline PE & $2007.3,2012.4$ & $2007.4,2013.1$ & $2005.1,2009.1$ & $2007.4,2013.2$ & $2008.3-2009.1$ \\
\hline $\mathrm{PH}$ & $2007.2,2009.3$ & $2007.2,2009.3$ & $2007.3,2010.2$ & $2007.3,2009.3$ & 2008.4-2009.1 \\
\hline PL & $2007.1,2013.1$ & $2000.1,2009.1$ & $2008.1,2013.1$ & $2001.1,2007.1$ & 2008.4-2009.1 \\
\hline RU & $2008.2,2010.3$ & $2009.4,2014.1$ & $2008.3,2012.3$ & $2008.4,2012.3$ & 2008.3-2009.1 \\
\hline $\mathrm{TH}$ & $2007.1,2009.4$ & $2008.4,2015.1$ & $2008.3,2010.2$ & $2007.3,2009.4$ & $2008.3-2009.2$ \\
\hline TR & $2010.2,2015.2$ & $2010.1,2016.2$ & $2007.4,2012.1$ & $2010.1,2016.2$ & 2008.3-2009.1 \\
\hline $\mathrm{ZA}$ & $2002.1,2009.1$ & $2002.3,2010.3$ & $2003.4,2009.1$ & $2002.3,2009.4$ & 2009.1-2009.2 \\
\hline PANEL & $2008.1,2000.2$ & $\begin{array}{c}\text { 2007.4 AE } \\
\text { 2001.3 EME }\end{array}$ & $2007.4,1998.2$ & $\begin{array}{l}2008.1,2011.1 \mathrm{AE} \\
2005.4,2009.2 \mathrm{EME}\end{array}$ & NA \\
\hline
\end{tabular}

Note: Highlighted dates are break dates that are consistent with the dates shown in the GFC column. Dates in italics indicate break dates that take place before the GFC dates for the US. Underlined dates are GFC dates that occur after the GFC begins in the US. The panel refers to the stacked aggregated values for inflation and inflation forecasts in the AE and EME. 


\section{SIKLOS Inflation Dynamics}

due to the GFC when the endogenously estimated date is within a year of the range of dates provided in the last column to be the same as in the case when dates are exogenously specified. ${ }^{26}$ The GFC column represents an exogenously dated break in inflation. Note that the GFC started earlier than in the US in several economies (identified by dates in italics). The GFC is associated with a change in the inflation process in only 3 to 5 of 12 economies when global inflation is proxied using observed data, but in more economies (up to 7) when 'global forces' are estimated from inflation forecasts. The same is true for EME with almost half impacted by the GFC though the impact is felt most when advanced economies' inflation rates are assumed to feed into domestic inflation rates. None of the breaks appear to be due to the introduction of inflation targeting. ${ }^{27}$ Nor do the breaks, with the possible exceptions of CA and MY, coincide with the exchange rate regime change chronology of Ilzetzki, Reinhart, and Rogoff (2019). ${ }^{28}$

While the GFC can account for many breaks in the data there is considerable heterogeneity in the dating of breaks in the inflation process with many occurring either quite early in the sample, that is, in the early 2000s, or well after the GFC ended but possibly during the Eurozone's sovereign debt crisis (i.e., after 2012). The last row of the Table lists the dates when common breaks occur in $\mathrm{AE}$ and EME. These breaks capture quite well the finding for individual economies so that the GFC is seen as significant when the entire data set is used (i.e., a panel where $\mathrm{AE}$ and $\mathrm{EME}$ are stacked ${ }^{29}$ ) or when $\mathrm{AE}$ economies are grouped together while the GFC is only significant in the EME group of countries alone when the global factor is derived from inflation in AE only. Otherwise, the second break tends to take place early in the sample. While a specific association with the introduction of IT is not apparent the fact that breaks in inflation are estimated in the late 1990s and early 2000s is notable since this is the range of dates when inflation targeting was introduced in several EME (see Bordo and Siklos 2019).

Tables 3 and 4 report the coefficient estimates of the impact of global inflation on both individual economy inflation rates as well as the panel of AE and EME groups of economies. The highlighted values identify the coefficients that are statistically significant at least at the $10 \%$ level of significance with a distinction made between positive versus negative effects on domestic inflation.

\footnotetext{
${ }^{26}$ Recall these are from Dominguez, Hashimoto, and Ito (2012) who derive their estimates from countryspecific peak to through changes in real GDP.

${ }^{27}$ The appendix to Bordo and Siklos (2019) provides the dating of the introduction of inflation targeting (IT) in the data set used here. With the exception of $\mathrm{CZ}$ and KR, AE adopted IT before the sample over which the break tests are conducted.

${ }^{28}$ The appendix provides the relevant dates.

${ }^{29}$ Recall that the relevant regressions are based on mean estimates of the variables for the AE and EME groups of economies, respectively. Fixed effects are also included (not shown) in the estimation.
} 
Review of Economic Analysis 12 (2020) 203-233

Table 3 The Global Factor: Observed Inflation, Endogenously Estimated Breaks

\begin{tabular}{|c|c|c|c|c|c|c|c|c|}
\hline \multirow[t]{2}{*}{ Economy } & \multicolumn{3}{|c|}{ Observed - ALL } & \multicolumn{3}{|c|}{ Forecast - AE } & \multicolumn{2}{|c|}{$\begin{array}{c}\text { Observed - No } \\
\text { Breaks }\end{array}$} \\
\hline & $1^{\text {st }}$ & $2^{\text {nd }}$ & $3^{\text {rd }}$ & $1^{\text {st }}$ & $2^{\text {nd }}$ & $3^{\text {rd }}$ & ALL & $\mathrm{AE}$ \\
\hline $\mathrm{AU}$ & $-1.38(.00)$ & $.10(.47)$ & $-.54(.08)$ & $2.13(.01)$ & $-1.38(.01)$ & $.58(.00)$ & $-.19(.00)$ & $-.49(.00)$ \\
\hline $\mathrm{CA}$ & $.28(.10)$ & $.00(.97)$ & $-.96(.02)$ & $-.30(.80)$ & $.50(.03)$ & $-.48(.01)$ & $-.07(.17)$ & $-.18(.07)$ \\
\hline $\mathrm{CZ}$ & $-.05(.82)$ & $.62(.06)$ & $-.71(.07)$ & $-2.55(.00)$ & $2.28(.00)$ & $.84(.23)$ & $.54(.00)$ & $.97(.00)$ \\
\hline EZ & $.13(.25)$ & $-.21(.00)$ & $-.43(.00)$ & $.25(.19)$ & $.30(.00)$ & $-.44(.10)$ & $-.14(.01)$ & $-.01(.95)$ \\
\hline GB & $48(.00)$ & $.26(.05)$ & $.23(.04)$ & $-2.29(.00)$ & $-.51(.14)$ & $-.37(.00)$ & .32(.00) & .49(.00) \\
\hline IL & $1.25(.54)$ & $.79(.08)$ & $-.92(.00)$ & $4.72(.00)$ & $-.43(.90)$ & $.03(.94)$ & $.66(.01)$ & $.35(.43)$ \\
\hline JP & \multicolumn{3}{|c|}{$.04(.20)$} & $1.07(.00)$ & $1.00(.02)$ & $.78(.01)$ & $.04(.08)$ & $.07(.24)$ \\
\hline KR & $-.25(.11)$ & $-.33(.70)$ & $.68(.01)$ & $.60(.02)$ & $-1.86(.00)$ & $-.41(.00)$ & $-.01(.92)$ & $-.66(.08)$ \\
\hline $\mathrm{NO}$ & $-1.72(.00)$ & $.86(.00)$ & $-.97(.09)$ & $-1.80(.01)$ & $8.72(.00)$ & $-1.09(.00)$ & $.58(.00)$ & $-.23(.37)$ \\
\hline $\mathrm{NZ}$ & $-.71(.00)$ & $.30(.04)$ & $-.26(.50)$ & $.30(.67)$ & $1.06(.01)$ & $-.14(.57)$ & $-.18(.07)$ & $-.39(.02)$ \\
\hline SE & $1.14(.00)$ & $-.12(.25)$ & $-.33(.00)$ & $-1.31(.00)$ & $.47(.39)$ & $-.09(.88)$ & $-.04(.73)$ & $-.31(.07)$ \\
\hline US & $-.17(.03)$ & $.91(.00)$ & $-1.17(.00)$ & $-.37(.30)$ & $1.57(.00)$ & $-.39(.10)$ & $-.08(.19)$ & $.04(.78)$ \\
\hline 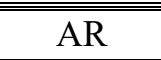 & ".26(.02) & - $-.43(.06)$ & - $-.16(.06)$ & "6.05(.00) & (2.84(.35) & $=9.99(.00)$ & $=-.20(.32)$ & $\begin{array}{l}-.47(.35) \\
\end{array}$ \\
\hline BR & $.53(.04)$ & $-.16(.18)$ & $.15(.84)$ & $1.45(.10)$ & $-.08(.82)$ & $-1.1(.17)$ & $-.32(.11)$ & $-.53(.11)$ \\
\hline $\mathrm{CL}$ & $.84(.07)$ & $.21(.83)$ &,$- 19(.83)$ & $-.20(.81)$ & $-.87(.23)$ & $-1.35(.47)$ & $-.79(.04)$ & $.76(.04)$ \\
\hline $\mathrm{CN}$ & $.49(.07)$ & $-1.99(.00)$ & $.05(.86)$ & \multicolumn{3}{|c|}{$-.04(.90)$} & $-.63(.00)$ & $-.33(.21)$ \\
\hline $\mathrm{CO}$ & $1.92(.00)$ & $.14(.23)$ & $-.04(.84)$ & $-.76(.48)$ & $.46(.22)$ & $.69(.33)$ & $.35(.08)$ & $-.29(.30)$ \\
\hline $\mathrm{HU}$ & $3.53(.00)$ & $-1.85(.00)$ & $-2.03(.06)$ & \multicolumn{3}{|c|}{$-.78(.00)$} & $-.14(.49)$ & $-.21(.49)$ \\
\hline ID & $26.69(.16)$ & $-.02(.97)$ & $-1.80(.02)$ & $-15.87(.00)$ & $3.10(.00)$ & $.70(.25)$ & $-.17(.64)$ & $-.002(.98)$ \\
\hline IN & $8.38(.00)$ & $.84(.04)$ & $2.85(.00)$ & $-5.23(.00)$ & $-5.43(.02)$ & $1.35(.00)$ & $1.46(.00)$ & $.23(.67)$ \\
\hline MX & $.77(.00)$ & $.42(.00)$ & $1.35(.00)$ & $.88(.27)$ & $-1.74(.00)$ & $.51(.00)$ & $.40(.00)$ & $.74(.00)$ \\
\hline MY & $.23(.21)$ & $.95(.00)$ & $-.80(.00)$ & $.44(.76)$ & $5.98(.00)$ & $-.39(.07)$ & $.73(.00)$ & $.94(.00)$ \\
\hline $\mathrm{PE}$ & $.30(.17)$ & $.60(.04)$ & $-2.03(.00)$ & $-1.21(.03)$ & $7.98(.01)$ & $-.97(.07)$ & $-1.8(.53)$ & $.07(.80)$ \\
\hline $\mathrm{PH}$ & $.07(.76)$ & $1.08(.02)$ & $-.53(.10)$ & $6.42(.00)$ & $3.18(.00)$ & $.51(.00)$ & $.77(.00)$ & $-.004(.99)$ \\
\hline $\mathrm{PL}$ & $-1.68(.00)$ & $.36(.02)$ & $-.41(.04)$ & $-4.19(.00)$ & $.26(.27)$ & $-1.28(.17)$ & $-.63(.00)$ & $-.68(.01)$ \\
\hline RU & $-1.28(.04)$ & $2.72(.00)$ & $-.40(.36)$ & $3.75(.00)$ & $.98(.30)$ & $.70(.12)$ & $-.23(.30)$ & $-.04(.89)$ \\
\hline $\mathrm{TH}$ & $-9.15(.00)$ & $-2.82(.00)$ & $.20(.48)$ & $9.83(.02)$ & $1.87(.00)$ & $.66(.05)$ & $-.01(.97)$ & $.31(.43)$ \\
\hline TR & $.89(.01)$ & $-1.95(.03)$ & 1.73(.00) & $-.68(.85)$ & $-1.99(.00)$ & $.71(.05)$ & $-.22(.29)$ & $.21(.33)$ \\
\hline $\mathrm{ZA}$ & $1.34(.35)$ & $-2.00(.00)$ & $.24(.51)$ & $-4.75(.00)$ & $-8.08(.00)$ & $.22(.18)$ & $-.56(.02)$ & $-1.12(.00)$ \\
\hline PANEL & $.18(.19)$ & $.61(.00)$ & $1.34(.00)$ & $.28(.05)$ & $-1.42(.00)$ & $.80(.01)$ & $.84(.00)$ & $-.28(.00)$ \\
\hline
\end{tabular}

Note: p-values provided in parenthesis. See equation (1) for the estimated specification. Coefficients for $\alpha_{7}$ are shown and positive versus negative statistically significant coefficients are separately highlighted by color. 
SIKLOS Inflation Dynamics

Table 4 The Global Factor: Observed Inflation, Exogenous Breaks

\begin{tabular}{|c|c|c|c|c|}
\hline Economy & GFC & $\begin{array}{l}\text { Observed - } \\
\text { ALL }\end{array}$ & GFC & $\begin{array}{c}\text { Forecast - } \\
\text { AE }\end{array}$ \\
\hline $\mathrm{AU}$ & $.24(.61)$ & $-.21(.02)$ & $.06(.88)$ & $-.50(.00)$ \\
\hline $\mathrm{CA}$ & $.27(.58)$ & $-.09(.14)$ & $.21(.64)$ & $-.19(.06)$ \\
\hline $\mathrm{CZ}$ & $.67(.47)$ & $.53(.00)$ & $1.08(.23)$ & $.95(.00)$ \\
\hline EZ & $.21(.26)$ & $-.17(.00)$ & $-.09(.60)$ & $-.01(.90)$ \\
\hline GB & $1.00(.02)$ & $.18(.06)$ & $1.04(.01)$ & $.31(.03)$ \\
\hline IL & $2.31(.03)$ & $.67(.01)$ & $3.95(.01)$ & $.90(.06)$ \\
\hline $\mathrm{JP}$ & $.32(.12)$ & $.02(.30)$ & $.38(.07)$ & $.03(.62)$ \\
\hline KR & $.04(.91)$ & $-.01(.91)$ & $.45(.16)$ & $-.70(.00)$ \\
\hline $\mathrm{NO}$ & $.43(.58)$ & $.52(.02)$ & $1.85(.06)$ & $-.23(.36)$ \\
\hline $\mathrm{NZ}$ & $.56(.36)$ & $-.21(.05)$ & $.12(.84)$ & $-.39(.03)$ \\
\hline $\mathrm{SE}$ & $1.16(.00)$ & $-.13(.27)$ & $1.20(.00)$ & $-.40(.02)$ \\
\hline US & $-.03(.94)$ & $-.08(.31)$ & $-.34(.35)$ & $.07(.59)$ \\
\hline AR & $-2.00(.32)$ & $-.15(.47)$ & $-2.08(.30)$ & $-.37(.47)$ \\
\hline $\mathrm{BR}$ & $2.12(.16)$ & $-.45(.04)$ & $1.49(.29)$ & $-.68(.07)$ \\
\hline $\mathrm{CL}$ & $1.05(.28)$ & $-.69(.07)$ & $1.41(.14)$ & $.75(.05)$ \\
\hline $\mathrm{CN}$ & $-.49(.54)$ & $-.59(.00)$ & $1.32(.10)$ & $-.34(.19)$ \\
\hline $\mathrm{CO}$ & $-.29(.78)$ & $.38(.10)$ & $.69(.45)$ & $-.32(.26)$ \\
\hline $\mathrm{HU}$ & $-3.85(.00)$ & $.10(.57)$ & $-3.64(.00)$ & $-.10(.70)$ \\
\hline ID & $3.64(.03)$ & $-.62(.14)$ & $2.42(.11)$ & $-.06(.91)$ \\
\hline IN & $.46(.77)$ & $1.44(.00)$ & $2.51(.15)$ & $.17(.75)$ \\
\hline $\mathrm{MX}$ & $-.78(.20)$ & $.48(.00)$ & $-.11(.35)$ & $.76(.00)$ \\
\hline MY & $2.24(.00)$ & $.52(.00)$ & $2.92(.00)$ & $.81(.00)$ \\
\hline $\mathrm{PE}$ & $2.78(.00)$ & $-.26(.32)$ & $2.80(.00)$ & $.22(.41)$ \\
\hline $\mathrm{PH}$ & $1.95(.06)$ & $.47(.10)$ & $3.13(.00)$ & $-.32(.32)$ \\
\hline $\mathrm{PL}$ & $2.23(.03)$ & $-.73(.00)$ & $1.05(.31)$ & $-.70(.00)$ \\
\hline RU & $2.30(.03)$ & $-.35(.11)$ & $2.11(.04)$ & $-.17(.57)$ \\
\hline $\mathrm{TH}$ & $-2.38(.01)$ & $.13(.44)$ & $-2.17(.01)$ & $.29(.43)$ \\
\hline TR & $1.21(.30)$ & $-.33(.16)$ & $1.32(.14)$ & $.10(.67)$ \\
\hline $\mathrm{ZA}$ & $1.54(.20)$ & $-.61(.01)$ & $.71(.56)$ & $-1.10(.00)$ \\
\hline PANEL & $.61(.07)$ & $.79(.00)$ & $2.58(.00)$ & $-.96(.00)$ \\
\hline
\end{tabular}

Note: See note to Table 3

Globalization, at least as interpreted by the recent literature (see section 2), is generally viewed as generating a reduction in inflation. If this benchmark is used, then only South Africa meets the standard regardless of how global inflation is proxied or even whether breaks in the inflation process are included. Otherwise only a few economies see a reduction in inflation conditional on endogenously estimated breaks and when global inflation is proxied using observed inflation rates. They are: $\mathrm{AU}, \mathrm{EZ}$, and GB among the $\mathrm{AE}$ and ID and TH among the EME. A reduction in inflation is obtained in $\mathrm{HU}$, IN, and PL, in addition to ZA mentioned earlier when global 
inflation is proxied by a combination of inflation forecasts in AE. These countries belong to the EME group. In general, the breaks see a mix of positive and negative changes in the inflation process. Hence, if globalization is believed to have reduced inflation then the breaks do not seem to be linked to this phenomenon.

This is especially true for the panel estimates shown at the bottom of Table 3. Other than the middle break, when global inflation is proxied by one year ahead forecasts, the breaks in inflation see a rise in inflation. Only when breaks are ignored, and forecasts are used to measure the 'global forces' on inflation, is a reduction in mean inflation observed.

A similar picture emerges when an exogenous break is considered as shown in Table 4. Nevertheless, what is interesting is that the GFC appears to raise average inflation rates in several $\mathrm{AE}$ and EME regardless of how the global inflation proxy is defined. As remarked earlier (see Figure 2) both $\mathrm{AE}$ and EME experienced a surge of inflation which was soon reversed. It is likely that some of the results in Table 4 are sensitive to the dating of the GFC when it is exogenously imposed. On balance, that is, when panel estimates are considered (bottom of Table 4), global inflation depresses domestic inflation when it is proxied by the one year ahead forecast for AE; otherwise global inflation, based on observed data, raises mean inflation in $\mathrm{AE}$ and EME. The good news is that, whether exogenously imposed or endogenously estimated, links between global inflation and domestic inflation and the impact of breaks on inflation are broadly similar. Moreover, while global inflation exerts a significant impact on domestic and regional inflation rates, it is clearly sensitive to the period examined. There is, therefore, no simple narrative linking 'global forces' and inflation. This is consistent with Carney's remark mentioned earlier who did not indicate the sign of any influence of global inflation on domestic inflation rates.

This much is clear so far. First, global inflation exerts a significant effect on domestic inflation. Second, even if we estimate a model of inflation that contains the usual variables and is augmented by forward-looking variables, that is, inflation and real GDP growth forecasts, there are still structural breaks that are necessary to improve the explanatory power of estimated regressions.

Two more tests are considered. There is an idiosyncratic element in the dating of breaks in inflation at the level of individual economies. A comparison, however, with the results for $\mathrm{AE}$ and EME suggests that many economies, other than during the GFC and its aftermath, experienced a shift in inflation in the earlier parts of the sample when inflation reduction policies were in place in $\mathrm{AE}$ and beginning to be introduced more widely in EME. In addition, estimates of global inflation also suggest strong interdependence in inflation rates though more so among AE than among EME. Accordingly, I next consider the spillover of inflation rates in AE versus EME relying on a test of contagion. Dungey, Fry, González-Hermosillo and Martin (2005) reviewed the methodologies with a more recent and more general update given by 
Rigobon (2019). Although other forms of contagion have since been defined Rigobon (2019) points out that contagion and spillovers, while not necessarily synonymous, are fundamentally similar concepts. In Forbes and Rigobon (2002) contagion refers to an increase in correlation between series in a crisis period relative to more "normal" times. Dungey et. al. (2005) suggest that differences in definitions of contagion are "minor". Since volatility also tends to rise during crisis conditions a natural way to think about contagion is to focus on changes in volatility. Unfortunately, changes in volatility need not occur only under crisis conditions. Interdependence is a better way then to characterize an increase in volatility when there is no contagion. Therefore, identification of crisis periods is critical. As we have seen, not all structural breaks are associated with a crisis but can, for example, reflect a change in policy regimes.

Table 5 presents the results of tests of 'contagion' or spillovers between global inflation and combined global inflation forecasts for a panel of data aggregated at the level of AE and EME as well as for the AE and EME groups of economies separately. Following Rigobon (2019), and given the heterogeneity of inflation performance across AE and EME as well as within each of these groups, the tests are also carried out for the 'corner solutions' of those with the highest inflation (and inflation forecasts) or lowest inflation rates over time. ${ }^{30}$

Following Dungey et. al. (2005) I write a version of the Forbes-Rigobon specification as follows:

Table 5 'Contagion’ Between Observed and Expected Inflation

\begin{tabular}{|c|c|c|c|c|c|c|}
\hline & $\begin{array}{c}\text { INF vs F1 } \\
\text {-ALL }\end{array}$ & $\begin{array}{c}\text { INF vs F1 } \\
- \text { AE }\end{array}$ & $\begin{array}{c}\text { INF vs F1 } \\
\text { EME }\end{array}$ & $\begin{array}{c}\text { F1 vs INF } \\
\text {-ALL }\end{array}$ & $\begin{array}{c}\text { F1 vs INF } \\
- \text { AE }\end{array}$ & $\begin{array}{c}\text { F1 vs INF } \\
\text { EME }\end{array}$ \\
\hline Min & $.72(.00)$ & $.21(.21)$ & $.04(.96)$ & $.26(.03)$ & $.25(.29)$ & $.46(.00)$ \\
\hline Contagion & \multicolumn{2}{|c|}{$6.04(.05)$} & \multicolumn{2}{|c|}{$5.55(.08)$} & \multicolumn{2}{c|}{$1.50(.47)$} \\
\hline Max & $-.41(.09)$ & $.36(.21)$ & $-.84(.03)$ & $.10(.39)$ & $.43(.02)$ & $-.12(.51)$ \\
\hline Contagion & \multicolumn{2}{|c|}{$3.94(.14)$} & \multicolumn{2}{|c|}{$9.10(.01)$} & \multicolumn{2}{c|}{$3.35(.19)$} \\
\hline Mean & $-.69(.00)$ & $.07(.70)$ & $-2.22(.00)$ & $.23(.00)$ & $.60(.00)$ & $-.02(.86)$ \\
\hline Contagion & \multicolumn{2}{|c|}{$1.10(.58)$} & \multicolumn{2}{|c|}{$3.47(.18)$} & \multicolumn{2}{c|}{$.10(.95)$} \\
\hline
\end{tabular}

Note: test based on system (2). The system was estimated via GMM with 2 lags of the dependent and independent variables (except the dummies) as instruments. P-values given in parenthesis

\footnotetext{
${ }^{30}$ Since the data are aggregated different countries (or economies) are represented over time.
} 
Review of Economic Analysis 12 (2020) 203-233

$$
\begin{aligned}
& \bar{\pi}_{\mathrm{t}}^{\mathrm{o}}=\theta_{1,2} \bar{\pi}_{\mathrm{t}}^{\mathrm{e}}+\lambda_{1,2} \bar{\pi}_{\mathrm{t}}^{\mathrm{e}} \bullet \mathrm{D}_{\mathrm{t}}+\xi_{\mathrm{t}}^{\mathrm{o}} \\
& \tilde{\bar{\pi}}_{\mathrm{t}}^{\mathrm{e}}=\theta_{2,1} \bar{\pi}_{\mathrm{t}}^{\mathrm{o}}+\lambda_{2,1} \bar{\pi}_{\mathrm{t}}^{\mathrm{o}} \bullet \mathrm{D}_{\mathrm{t}}+\xi_{\mathrm{t}}^{\mathrm{e}} \\
& \mathrm{o} \neq \mathrm{e}
\end{aligned}
$$

The system of equations (2) consists of the (standardized) global inflation and global inflation expectations ${ }^{31}$, that is, both series are scaled by their standard deviations during 'normal' times, the variables $\bar{\pi}_{\mathrm{t}}^{\mathrm{o \neq e}}$ represent observed global inflation (o) or expected global inflation (e) for a panel consisting of both AE and EME series stacked ${ }^{32}$ or, separately, for either AE or EME economies. The null $\mathrm{H}_{0}: \lambda_{\mathrm{i}, \mathrm{j}}=0, \forall \mathrm{i} \neq \mathrm{j}$ indicates the presence and strength of the contagion or spillover effects.

Table 5 indicates, first, spillovers between global observed and global expected inflation are sensitive according to whether we consider mean, maximum or minimum inflationary experiences in both $\mathrm{AE}$ and EME, and whether or not we combine the two groups of economies. For example, in the case where AE and EME are considered jointly, whereas at the mean and for the worst performing economies in terms of global inflation is lower during the time the world experienced the GFC (i.e., pre-GFC; $\lambda_{1,2}<0$ ), the reverse is true for the best performing economies (i.e., max). Similarly, global expected inflation is higher in crisis than in 'normal' times on average and for economies with the lowest global inflation rates while expectations did not respond for economies where inflation rates are highest. When the $\mathrm{AE}$ are considered alone there is no evidence that global inflation is different in crisis versus pre-crisis times. The reverse is largely true for EME where global inflation is lower due to the GFC on average and for the worst inflation performers in that region. Similarly, global inflation expectations in AE rise in the GFC relative to 'normal' times, again at the mean as well as at the highest global inflation rates. The only similar impact for the EME is found for economies in that region with the lowest global inflation rates.

Turning to contagion or spillovers the null cannot be rejected in most cases indicating, especially at the mean, that there are no spillovers between inflation and expected inflation. Contagion is found, however, among the best performing economies in terms of global inflation when both $\mathrm{AE}$ and EME are stacked together as well as among the AE economies alone. Stated differently, even if there are spillovers between observed and forecasted global inflation this is limited to the 'best' performers among the AE and EME. Hence, if global inflation or inflation

\footnotetext{
${ }^{31}$ Both the combined forecasts and WEO forecasts are considered. However, in view of the widely agreed conclusion that forecast combinations outperform individual forecasts (e.g., Timmermann 2006) I report only this case below. Others are available on request.

32 The model is estimated with fixed effects.
} 


\section{SIKLOS Inflation Dynamics}

expectations impact country or economy-specific inflation rates there can be a disconnect between the determination of global inflation and expected inflation.

Next, I ask how global shocks impact inflation and selected other determinants. For this case the panel of AE and EME is considered. I estimate a panel local projections version of equation (1) which is written

$$
\mathbf{y}_{\mathrm{t}+\mathrm{h}}=\boldsymbol{\alpha}_{\mathrm{h}}+\psi_{\mathrm{h}}(\mathrm{L}) \mathbf{y}_{\mathrm{t}-1}+\beta_{\mathrm{h}} \pi_{\mathrm{t}}^{\mathrm{h}}+\boldsymbol{v}_{\mathrm{h}, \mathrm{t}}
$$

where $\mathbf{y}$ is a vector of endogenous variable, that is, $\left(\pi_{t}, \pi_{t}^{\mathrm{e}}, \mathrm{g}_{\mathrm{t}}^{\mathrm{e}}, \mathrm{i}_{\mathrm{t}}, \pi_{\mathrm{t}}^{\mathrm{G}}\right)^{\prime}$ and where, to conserve degrees of freedom, commodity prices and a dummy for the GFC are treated as exogenous variables. The addition of the GFC dummy seems appropriate given the earlier discussion. ${ }^{33} h$ is set to 10 periods, $\mathrm{L}=2$ and, by way of comparison, point estimates from a conventional VAR are also shown in Figure 3. ${ }^{34}$

The impulse responses reveal that global inflation forecasts have no significant impact on inflation or real exchange rates. Instead, rising global inflation forecasts raise domestic inflation expectations and real GDP growth forecasts as well as domestic policy rates. Hence, while much of the relevant literature has focused on the link between global and domestic inflation, shocks from abroad also broadly impact domestic monetary policy. Perhaps more striking is that domestic shocks impact global inflation expectations. Therefore, although policy makers have expressed concern about the inflationary consequences of external inflation shocks, domestic shocks themselves have implications for global inflation expectations. This possibility is one that the extant literature has tended to be silent about. Notably, both rising observed and expected domestic inflation in the AE and EME results in higher global inflation, the same result holds for a positive real GDP expectations shock. Similarly, a depreciation shock raises global inflation expectations as does a rise in domestic policy rates.

A difficulty with the foregoing results is that they are informative only about mean responses. Yet, as shown earlier, the impact of global factors also differs between the best and

\footnotetext{
${ }^{33}$ Other dummies, given findings of structural breaks in inflation were also tried but the results discussed below are unchanged (not shown). A few illustrations are relegated to the appendix. Recall that the panel is estimated with fixed effects.

${ }^{34}$ To avoid clutter confidence bands for the conventional VARs are not shown. However, inference is largely the same for the local projections and the conventional VARs except for the impact of a shock to the policy rate $(i)$ on global inflation expectations (F1 FCAST) which is statistically insignificant at all lags while negative at lag 6 in the local projections case. Most, not all, impulse responses are similar when global observed inflation is used. For example, higher global inflation reduces real GDP growth forecasts but, as shown below, the reverse holds for global inflation forecasts. I return to the implication of some of these differences in the conclusions.
} 
Review of Economic Analysis 12 (2020) 203-233

Figure 3 Impulse Responses: The Impact of Global Expected Inflation Shocks
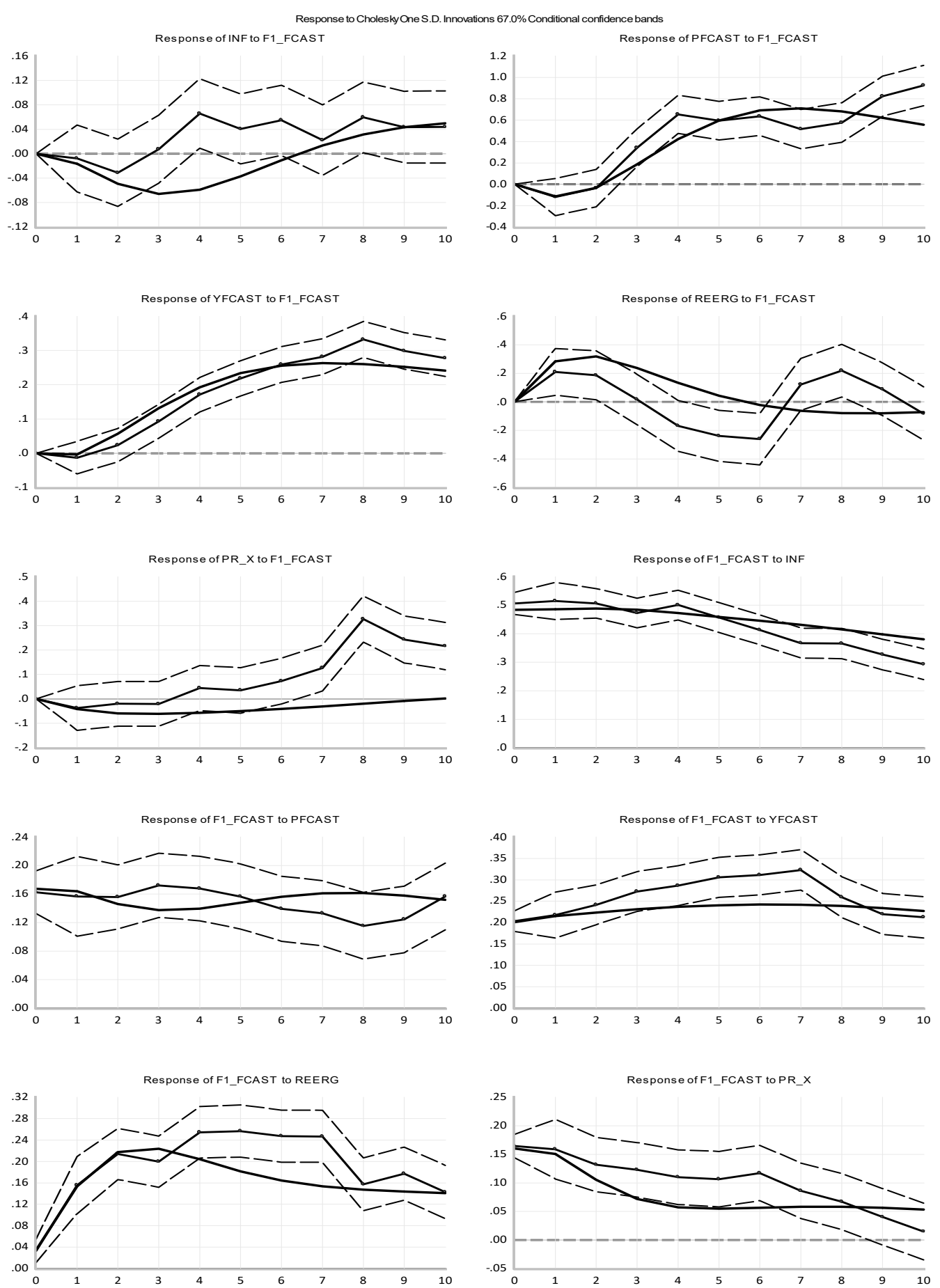


\section{SIKLOS Inflation Dynamics}

Note: Thick solid lines are impulse responses estimated via a standard Cholesky decomposition with the variable ordering as indicated in equation (3). Thin solid lines are impulse responses estimated via a local projection. Again, see equation (3). $80 \%$ confidence intervals are shown as dashed lines

worst performing economies in terms of inflation. Therefore, I supplement the analysis in Figures 3 with quantile local projections. This implies estimating a version of equation (3) written as

$$
\mathrm{Q}\left(\mathbf{y}_{\mathrm{t}+\mathrm{h}} \mid \tau\right)=\boldsymbol{\alpha}_{\mathrm{h}}(\tau)+\psi_{\mathrm{h}}(\mathrm{L} \mid \tau) \mathbf{y}_{\mathrm{t}-1}+\beta_{\mathrm{h}}(\tau) \pi_{\mathrm{t}}^{\mathrm{h}}+\mathbf{v}_{\mathrm{h}, \mathrm{t}}(\tau)
$$

where $\mathrm{Q}$ represents the quantile local projection and $\tau$ are the quantiles. To conserve space, Figure 4 presents the impulse responses for $\tau=.1,25,75$, and .9. confidence intervals are also omitted to avoid clutter, but the dashed circles indicate lags where the impulse responses are statistically significant at the $80 \%$ level. The top-left portion of Figure 4 suggests that global shocks (i.e., GLOBAL) negatively impact inflation in AE (i.e., INF_AE) at all but the 0.25 quantile after 4 and 5 lags. However, as the top-right portion of Figure 4 indicates a rise in global inflation raises inflation expectations (i.e., PFCAST_AE) in AE contemporaneously and after 1 lag. Thereafter, at all quantiles, the impulse responses are all insignificant.

Turning to the EME (bottom left and right hand side plots in Figure 4) we observe that global inflation shocks have no impact on inflation at the estimated quantiles shown while, as was true for $\mathrm{AE}$, a rise in global inflation raises inflation expectations in EME but only among the best performers in terms of inflation (i.e., at quantiles 0.1 and 0.25) after 7 to 10 lags. All these results underscore the heterogeneous nature of the impact of global inflation on domestic inflation, highlight the diversity of the impact of global shocks to inflation expectations and the differential responses to global shocks as between AE and EME. Once again, there is no simple narrative that explains links between global inflation shocks and the dynamics of domestic inflation.

\section{Conclusions}

There is little doubt that domestic inflation rates are influenced by global inflationary developments despite monetary policy and exchange rate regimes that are intended to shield inflation from external shocks. Nevertheless, this result misses at least three features of the data that the extant literature has under-reported. First, there is considerable heterogeneity in the size and sign of the impact of global shocks on domestic inflation in the sample of 29 advanced and emerging market economies examined. Moreover, there are no simple distinctions between the 
Figure 4 Impulse Responses: Quantile Local Projections for the Impact of Global Inflation Shocks
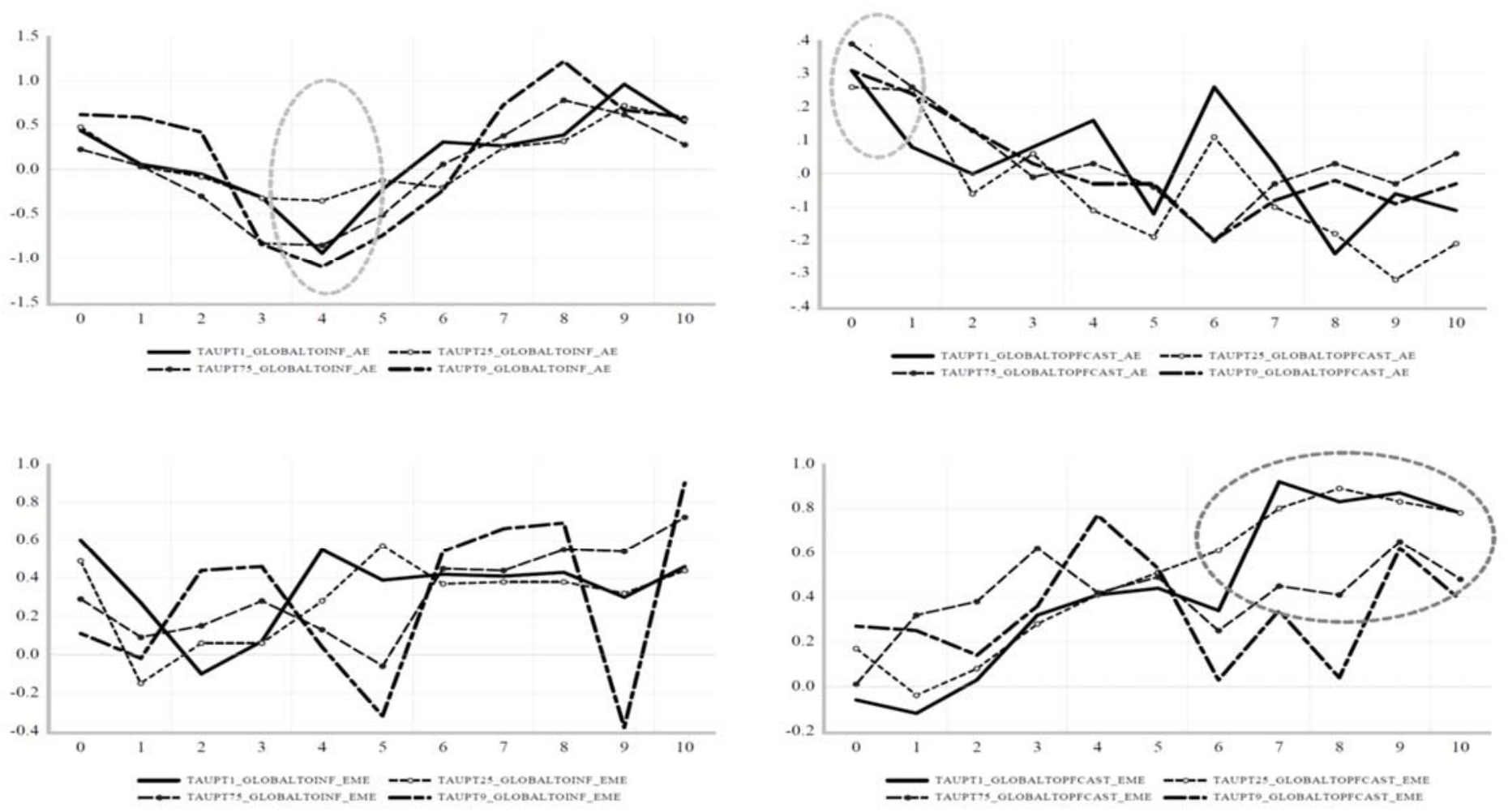

Note: TAUPT indicates the impulse response estimated at quantiles 0.1 (1), 0.25 (25), 0.75 (75), and 0.9 (9). The top set of impulse responses show the response of (observed) inflation (INF AE) or inflation forecasts (PFCAST AE) to a global inflation shock (GLOBAL). The bottom set of impulse responses show the case of EME. The circles indicate those lags where some or all of the IR are statistically significant at the $80 \%$ level. Estimates are based on the Epanechnikov kernel sparsity, covariances are estimated via the Markov Chain Marginal bootstrap, the Huber sandwich, and Hall-Sheather bandwidth. 


\section{SIKLOS Inflation Dynamics}

$\mathrm{AE}$ and EME when it comes to how global inflation, whether of the observed or forecasted variety, impacts domestic inflation. Second, whereas previous studies have focused on how external inflation shocks impact domestic inflation, there is a significant link between domestic inflation, at the level of advanced and emerging market economies, and global inflation. Third, how global inflation shocks impact domestic inflation rates depends in part on whether the shock stems from observed or expected inflation.

Almost all previous studies allow only a role for globally observed inflation. Yet, as central banks around the world have become more forward-looking, there ought to be more explicit recognition that domestic inflation is also partly determined by global expected inflation. Finally, one important difference between $\mathrm{AE}$ and EME inflation performance remains. Observed inflation has a significant impact on expectations in $\mathrm{AE}$ while there is no impact from expectations in the other direction. In contrast, there is a clear tendency for expected inflation to influence observed inflation. When both economies are jointly examined there is a bidirectional relationship between observed inflation and inflation expectations.

Nevertheless, the strength and sign of the links are sensitive according to whether one examines mean performance versus economies that are the best or the worst performers in terms of inflation. Therefore, the impact of global factors in individual economies is partly a function of their performance vis-à-vis others in either the advanced or emerging market group of economies. Indeed, spillover effects in inflation from global to domestic inflation are found only for the AE and, globally, only for the best inflation performers.

If the global element driving individual country inflation rates persists then existing policy rules that have served us reasonably need not be modified but central banks should provide clearer explanations and regularly update the public on the degree to which external pressures drive inflation. Currently, this type of communication tends to be more episodic in nature. Only time will tell whether standard monetary policy rules, routinely used by central bankers to communicate the stance of monetary policy, will need to be explicitly modified to take these eternal pressures into account. Nor is this a small open economy problem. Even systemically important economies like the U.S. have begun to take external factors into account when deliberating the appropriate stance of monetary policy.

At least three extensions should be considered before the results presented in this study are seen as more definitive. First, instead of conducting some of the tests at a high level of aggregation, additional estimation at the country or economic-specific level needs to be generated. Panel or global VARs may be insightful in this regard (e.g., see Bordo and Siklos 2019, Feldkircher and Siklos 2019). Next, a deeper investigation of the connection between individual inflation performance in relation to its peers among either the AE or EME should be conducted. Finally, it would be desirable to combine observed and expected inflation to get a more realistic measure of how global factors impact domestic inflation. These extensions are left for the future. 


\section{References}

Altansukh, G, R. Becker, G. Bratsiotis, and D. R. Osborn (2018), "Structural breaks in International Inflation Linkages in OECD Countries", discussion paper 240, Centre for Growth and Business Cycle Research, University of Manchester.

Altansukh, G, R. Becker, G. Bratsiotis, and D. R. Osborn (2017), "What is the Globalisation of Inflation?", Journal of Economc Dynamics and Control 74 (January): 1-27.

Bai, J. (2010), Common Breaks in Means and Variances for Panel Data, Journal of Econometrics 157: 78-92.

Bai, J. and P. Perron (1998). Estimating and Testing Linear Models with Multiple Structural Changes, Econometrica, 66, 47-78.

Bai, J. and P. Perron (2003a). Computation and Analysis of Multiple Structural Change Models, Journal of Applied Econometrics, 6, 72-78.

Bai, J. and P. Perron (2003b). Critical Values for Multiple Structural Change Tests, Econometrics Journal, 18, 1-22.

Bailliu, J., and P. Blagrave (2010), The Transmission of Shocks to the Chinese Economy in a Global Context: A Model-Based Approach, Bank of Canada working paper 2010-17, July.

Ball, L., and N. Mankiw (1995), Relative Price Changes as Aggregate Price Shocks, Quarterly Journal of Economics 110 (February): 161-193.

Belkhonja, M., and I. Mootami (2016), Long Memory and Structural Change in the G7 Inflation Dynamics, Economic Modelling 54 (April): 450-62.

Bems, R., F. Caselli, F. Grigoli, B. Gruss, and W. Lian (2018), Is Inflation Domestic or Global? Evidence from Emerging Markets, IMF working paper 18/241.

Bernanke, B. (2008) Outstanding Issues in the Analysis of Inflation, Chairman Ben S. Bernanke, at the Federal Reserve Bank of Boston's 53rd Annual Economic Conference, Chatham, Massachusetts, 9 June 2008, available at http://www.federalreserve.gov/newsevents/speech/bernanke20080609a.htm.

Bernanke, B. (2007), Inflation Expectations and Inflation Forecasting', speech At the Monetary Economics Workshop of the National Bureau of Economic Research Summer Institute, Cambridge, $\quad$ Massachusetts, 10 July, available from https://www.federalreserve.gov/newsevents/speech/bernanke20070710a.htm.

Bernanke, B. (2002), Deflation: Making Sure It Doesn't Happen Here, speech before the National Economists Club, $21 \quad$ November, https://www.federalreserve.gov/boarddocs/speeches/2002/20021121/default.ht m

Bhatnagar, S., A.-K. Cormier, K. Hess, P. de Leon-Manlagnit, E. Martin, V. Rai, R. St-Cyr and S. Sarker (2017), Low Inflation in Advanced Economies: Facts and Drivers, Bank of Canada Staff Analytical Notes 2017-16. 
Bohl, M., D. Mayes, and P. Siklos (2011), The Quality of Monetary Policy and Inflation Performance: Globalization and Its Aftermath, The Manchester School 79 (June): 617-645.

Bordo, M., and P. Siklos (2016), Central Bank Credibility: An Historical and Quantitative Exploration, NBER working paper 20824, January 2015 (with M. Bordo). In Central Banks at a Crossroads: What Can We Learn From History? Edited by M.D. Bordo, Ø. Eitrheim and M. Flandreau (Cambridge, Mass.: Cambridge University Press), pp. 62-144

Bordo, M., and P. Siklos (2018), Central Banks: Evolution and Innovation in Historical Perspective, with M.D. Bordo, in_Sveriges Riksbank and the History of Central Banking, (eds) Rodney Edvinsson, Tor Jacobson and Daniel Waldenstrom (Cambridge, Mass.: Cambridge University Press), pp. 26-89.

Bordo, M., and P. Siklos (2019), The Transformation and Performance of Emerging Market Economies Across the Great Divide of the Global Financial Crisis, NBER working paper 26342, October.

Borio, C., Erdem, A. Filardo, and B. Hofmann (2015), The Costs of Deflation: A Historical Perspective, Quarterly Review March: 31-54.

Borio, C., and A. Filardo (2007), Globalisation and Inflation: New Cross-Country Evidence of the Global Determinants of Domestic Inflation, BIS Working Papers, no 227.

Borio, C., and A. Filardo (2006), Globalization and Inflation: New Cross-Country Evidence on the Global Determinants of Domestic Inflation, BIS working paper No. 227.

Borio, C., and A. Filardo (2004), Looking back at the international deflation record, North American Journal of Economics and Finance 15(December): 287-311.

Brittan, S. (2013), Go For Growth, Inflation is Still a Long Way Away, Financial Times, 25 July.

Brouillette, D., and L. Savoie-Chabot (2017), Global Factors and Inflation in Canada $<$ Bank of Canada Staff Analytical Notes 2017-17.

Buiter, W. (2008), Central Banks and Financial Crises, paper presented at Federal Reserve Bank of Kansas City's symposium on Maintaining Stability in a Changing Financial System, at Jackson Hole, Wyoming, August 21-23, 2008, post-symposium version, September, London School of Economics discussion paper 619.

Burdekin, R., and P. Siklos (2004), Fears of Deflation and the Role of Monetary Policy, in R. Burdekin and P. Siklos (Eds.), Deflation (Cambridge: Cambridge University Press), pp. 128.

Carney, M. (2017), [De]Globalisation and Inflation, 2017 IMF Michel Camdessus Lecture, 18 September, available from www.bankofengland.co.uk/speeches.

Chen, H., and P. Siklos (2020), Oceans Apart? China Versus the Systemically Important Economies, Hong Kong Institute for Monetary Research working paper (forthcoming).

Ciccarelli, M., and B. Mojon (2010), Global Inflation, Review of Economics and Statistics 92 (August): 524-535. 
Clark, and T. Davig (2009), The Relationship Between Inflation and Inflation Expectations, working paper, 30 November 2009, Federal Open Market Committee, available from www.federalreserve.gov.

Dominguez, K, Y. Hashimoto, and T. Ito (2012), International Reserves and the Global Financial Crisis, Journal of International Economics 88: 388-406.

Dungey, M., R. Fry, B. Gonzáles-Hermosillo, and V. Martin (2005), Empirical Modelling of Contagion: A Review of Methodologies, Quantitative Finance 5 (February): 9-24.

Dungey, M., and J. Pitchford (2000), The Steady Inflation Rate of Economic Growth, The Economic Record 76 (December): 386-400.

Eickmeier, S., and M. Kühnlenz (2018), China's Role in Global Inflation Dynamics, Macroeconomic Dynamics 22 (March): 225-54.

Eichengreen, B. (1992), Golden Fetters (Oxford: Oxford University Press).

Eo, Y. (2015), Structural Change in Inflation Dynamics: Multiple breaks at Different Dates for Different Parameters, Studies in Nonlinear Dynamics and Econometrics 20(3): 211-31.

Fedlkircher, M., and P. Siklos (2019), Global Inflation Dynamics and Inflation Expectations, International Review of Economics and Finance 64: 217-41.

Forbes, K. (2019), Has Globalization Changed the Inflation Process?, BIS working paper No. 791, June.

Fried, J. (1973), Inflation-Unemployment Trade-Offs Under Fixed and Floating Exchange Rates, Canadian Journal of Economics 6 (February): 43-52.

Fuhrer, J. C. (2009), Inflation Persistence, Federal Reserve Bank of Boston working paper 0914.

Goodfriend, M., and R. King (2013), The Great Inflation Drift, in M. D. Bordo and A. Orphanides (Eds), The Great Inflation (Chicago: University of Chicago Press) pp. 181-209.

Ha, J., A. Kose, and F. Liesolotte Ohnsonge (2019), Inflation in Emerging and Developing Economies, CAMA working paper 2019-22.

Ilzetzki, E., C. M. Reinhart, K. S. Rogoff (2019), Exchange Arrangements Entering the 21st Century: Which Anchor Will Hold?, Quarterly Journal of Economics 134 (May): 599-646.

International Monetary Fund (2013), World Economic Outlook, April.

King, M. (2008), Letter from the Governor to the Chancellor of the Exchequer, Bank of England, 16 June, available from https://www.bankofengland.co.uk/sitemap/letters.

Mehrotra, A., and J. Yetman (2018), Decaying Expectations: What Inflation Forecasts Tell Us About the Anchoring of Inflation Expectations, International Journal of Central Banking 14(5): 55-101.

Morris, S., and H. Shin (2002), The Social Value of Public Information, American Economic Review 92 (December): 152-1534.

Parker, (2018), How Global is Global Inflation?, Journal of Macroeconomics 58: 174-197.

Rigobon, R. (2019), Contagion, Spillover, and Interdependence, Economía 19 (Spring): 69-99. 
Rogoff, K. (2006), Impact of Globalization on Monetary Policy, in New Economic Geography: Effects and Policy Implications, Proceedings of the Symposium of the Federal Reserve Bank of Kansas City, Kansas City, pp. 265-305.

Sargent, T, (1999), The Conquest of American Inflation (Princeton, N.J.: Princeton University Press).

Schoder, C. (2013), The Fundamentals of Sovereign Debt Sustainability: Evidence from 15 OECD Economies, Macroeconomic Policy Institute working paper 107, February 2013.

Siklos, P. (2020), Living in the Rear View Mirror: Lessons from Japan for the Eurozone and the US?, Institute for Monetary and Economic Studies working paper, Bank of Japan, forthcoming.

Siklos, P. (2018), The Macroeconomic Response to Real and Financial Factors, Commodity Prices, and Monetary Policy: International Evidence, SEACEN discussion paperWP7/2018, October.

Siklos, P. (2017), Central Banks Into the Breach (Oxford: Oxford University Press).

Siklos, P. (2013), Sources of Disagreement in Inflation Forecasts: An International Empirical Investigation, Journal of International Economics 90(1): 218-231.

Siklos, P. (2010), Relative Price Shocks, Inflation Expectations and the Role of Monetary Policy, in R. Fry, C. Jones, and C. Kent (Eds.), Inflation in an Era of Relative Price Shocks (Sydney: Reserve Bank of Australia), pp. 259-297.

Siklos, P., and Y. Zhang (2010), Identifying the Shocks Driving Inflation in China, Pacific Economic Review 15 (May): 204-223.

Stock, J., and M. Watson (2019), Slack and Cyclically Sensitive Inflation, NBER working paper 25987, June.

Svensson, L. (2002), Social Value of Public Information: Morris and Shin (2002) Is Actually Pro Transparency, Not Con. American Economic Review 96 (March): 453-455.

Timmermann, A. (2006), Forecast Combinations, in Handbook of Economic Forecasting, vol. 1, G. Elliott, C. Granger, and A. Timmermann (Eds.), Amsterdam: North-Holland. pp. 13696.

Wadhwani, S. (2013), Applaud Central Banks 'Soft' on Inflation', Financial Times, 11 March.

Wolf, Martin (2008) How Imbalances Led to Credit Crunch and Inflation, Financial Times column, June 17.

Woodford, M. (2012), Methods of Policy Accommodation at the Zero Lower Bound, in The Changing Policy Landscape, Proceedings of the Economic Symposium, Federal Reserve Bank of Kansas City, pp. 185-288.

Zhang, C., and H. He (2016), Globalization and Changing Inflation Dynamics in China, Emerging Market Finance and Trade 52(3): 625-38. 